\title{
JULAD
}

Investing in rural people

\section{Scoping and Selecting}

\section{Setting Up}

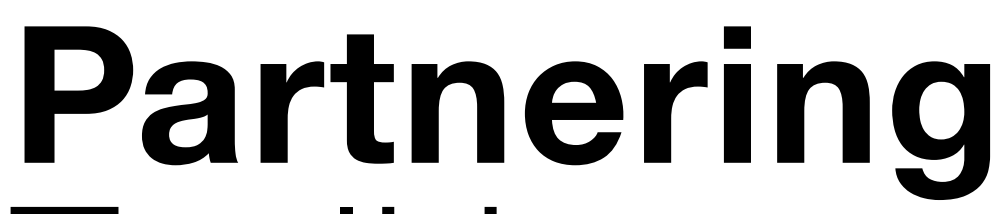

Toolkit

Practical tools for strengthening IFAD's partnerships

\section{Implementing}




\section{Table of contents}

Colophon | Abbreviations used

Introduction to the toolkit and phases of partnering

Scoping and Selecting Tools

TOOL $1 \quad$ Checklist for effective partnerships

TOOL 2 Identifying and prioritizing partnerships

TOOL $3 \quad$ Prospective partnership assessment

Setting Up Tools

TOOL $4 \quad$ Negotiating and documenting a partnership agreement

\section{Implementing Tools}

TOOL 6 Effective partnership management and communication

Monitoring and Reviewing Tools

TOOL $8 \quad$ Monitoring and reporting on partnerships

\section{Cross-cutting Tools}

TOOL $10 \quad$ Partnering with government 


\section{Colophon}

Authors: Jim Woodhill (AgriFoodNexus); Herman Brouwer (Wageningen Centre for Development Innovation); Hermine ten Hove (Wageningen Centre for Development Innovation)

Version 1, 21 June 2021

Cite as: IFAD (2021) Partnering Toolkit: Practical tools for strengthening IFAD's partnerships. Rome: IFAD

Copyright IFAD 2021. Licensed under CC-BY-NC 4.0 (CreativeCommons Attribution 4.0, https://creativecommons. org/licenses/by-nc/4.0/)

DOI: $10.18174 / 545231$.

Originator and contact person: Willem Wefers Bettink, Chief Partnership Officer, Global Engagement, Partnership and Resource Mobilization Division at IFAD.w.bettink@ifad.org

\begin{abstract}
Acknowledgements: The authors wish to thank the following IFAD staff for contribution through interviews, peer review and other support: Oana Denisa Butnaru, Partnership Officer, Funds Management Global Engagement, Partnership and Resource Mobilization (GPR) Division; Naoufel Telahigue, Country Director Near East, North Africa and Europe Division (NEN); Bernard Mwinyel Hien, former Country Programme Manager for Cameroon; Massimo Giovanola, Lead Technical Specialist for the Platform on Agricultural Risk Management (PARM) at IFAD; Mauro Martini, Remittances Officer of the Financing Facility for Remittances (FFR) at IFAD; Raniya Khan, Senior Technical Advisor to the Associate Vice-President Strategy and Knowledge Department (SKD); Sara-Ann Bridges, Policy and Results Specialist Operational Policy and Results Division (OPR); Nicole Carta, former Team Lead - Private Sector Partnerships; Ben Odoemena, Country Programme Officer for Nigeria; Alessia Valentini, Global Engagement, Partnership and Resource Mobilization (GPR) Division.
\end{abstract}

\begin{abstract}
About IFAD: The International Fund for Agricultural Development (IFAD) invests in rural people, empowering them to increase their food security, improve the nutrition of their families and increase their incomes. We help them build resilience, expand their businesses and take charge of their own development. IFAD is an international financial institution and specialized United Nations agency based in Rome, the UN's food and agriculture hub. Since 1978, IFAD has provided US\$22.4 billion in grants and low-interest loans to projects that have reached an estimated 512 million people.
\end{abstract}

About Wageningen Centre for Development Innovation: WCDI supports value creation by strengthening capacities for sustainable development. As the international expertise and capacity building institute of Wageningen University \& Research we bring knowledge into action, with the aim to explore the potential of nature to improve the quality of life. With approximately 30 locations, 6,500 members of staff and 12,500 students, Wageningen University \& Research is a world leader in its domain. An integral way of working, and cooperation between the exact sciences and the technological and social disciplines are key to its approach.

\section{Abbreviations used}

ACD IFAD Accounting and Controller's Division

ARRI Annual Report on Results and Impact of IFAD Operations

CCR COSOP Completion Review

CRR COSOP Results Review

CSR Corporate Social Responsibility

ORMS Operational Results Management System

COM IFAD Communications Division

CosoP Country Strategic Opportunity Programme

CPO Country Programme Officer

CD Country Director

ECG IFAD Environment, Climate, Gender and Social Inclusion Division

IOE Independent Office of Evaluation

GPR IFAD Global Engagement, Partnership and Resource Mobilization Division

GRIPS Grants and Investment Projects System

LEG IFAD Office of the General Counsel

LICs Low-Income Countries

MEL Monitoring, Evaluation, and Learning

MTR Mid-Term Review

MoU Memorandum of Understanding

MSP Multistakeholder Partnership

OIE Independent Office of Evaluation

ORMS Operational Results Management System

OPR Operational Policy and Results Division

PBAS Performance-based Allocation System

PDR Project Design Report

PMI IFAD Sustainable Production, Markets and Institutions Division

PMD IFAD Programme Management Department

PoLG Programme of Loans and Grants

RBA Rome-based agencies

RIA IFAD Research and Impact Assessment Division

RIDE Report on IFAD's Development Effectiveness

RMF Results Measurement Framework

LMICs Lower-Middle-Income Countries

SEC IFAD Office of the Secretary

SIDS Small (island) Developing States

SKD IFAD Strategy and Knowledge Department

SSTC South-South and Triangular Cooperation

UMICs Upper-middle-income countries

UNCTAD United Nations Conference on Trade and Development 


\section{Introduction to the toolkit and phases of partnership}

AIM OF THE TOOL

To introduce users to IFAD's

Partnering Toolkit and Partnership

Framework, and to the key phases

of partnering.

WHEN TO USE IT

When you are orienting yourself

to IFAD's approach to partnering

and need guidance on how the

partnering tools can help.

\section{Why use this guide, and how to use it}

Partnering is central to how IFAD works, to delivering on its commitment to sustainable and inclusive rural transformation, and to achieving the SDGs. This Partnering Toolkit supports implementation of the IFAD Partnership Framework, adopted by the Executive Board in September 2019. The Framework, based on IFAD's experience, aims to improve the prioritization, delivery, and monitoring of IFAD partnerships.

The tools pull together established good practices for partnering and integrate these with IFAD lessons and corporate processes. They offer IFAD staff a set of guides, processes, tips, checklists, and templates to be used in the day-to-day work of partnering.

There is no one "blueprint" to partnering. IFAD establishes partnerships with a large diversity of organizations in a wide range of contexts. Given this, the tools are intended to be used flexibly and adapted to your needs in a specific partnering situation. Most IFAD staff will already be involved in working with a diverse range of partnerships. So the tools are also designed help you at the point you find yourself in a partnership, be it to improve monitoring, to tackle delivery issues in a longstanding partnership, or to set up a new partnership.

The tools contain a lot of common sense, and they may reflect much of how you already operate. Yet in the course of day-to-day pressures, common sense steps and processes can be overlooked or forgotten, with negative effects on how well partnerships work. The tools provide a basis for checking that, as far as possible, good practice is being followed in all of IFAD's partnering.

IFAD staff possess a diverse range of partnering experience and capability. If you are relatively new to partnering, you may find it helpful to work through the entire set of tools and use them in a stepby-step fashion. If you are an old hand at partnering, the tools can help you to double check that all key issues have been considered, and they can serve as a resource you can use to support others in brokering IFAD's partnerships.

\section{"Partnerships are collaborative \\ relationships between institutional \\ actors that combine complementary \\ strengths and resources to achieve \\ common goals and objectives"}

IFAD Partnership Framework, September 2019 


\section{What is the partnership framework?}

The IFAD Partnership Framework provides an integrated approach to prioritizing, strengthening, and monitoring partnerships within IFAD's business processes. The need for such a framework and the associated tools arose from evaluations and consultations that identified the importance of strengthening IFAD's partnering processes-particularly in relation to prioritization, monitoring, and reporting.

The Framework has six core partnering objectives that work together in an integrated manner to help achieve IFAD's mission.

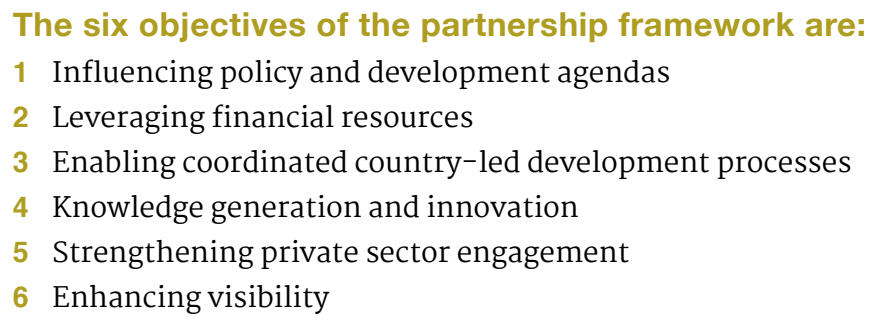

Realizing these objectives contributes to three key outcomes: (i) country impact at scale; (ii) a better enabling environment for rural development; and (iii) capable and effective partner organizations. Building on IFAD's existing practice of partnering, this requires that IFAD become more strategic, targeted, and results-oriented in its partnerships. These outcomes and the objectives provide highlevel orientation for prioritizing IFAD's partnerships and for assessing partnering performance. They align with IFAD's theory of change and with the IFAD Strategic Framework 2016-2025.

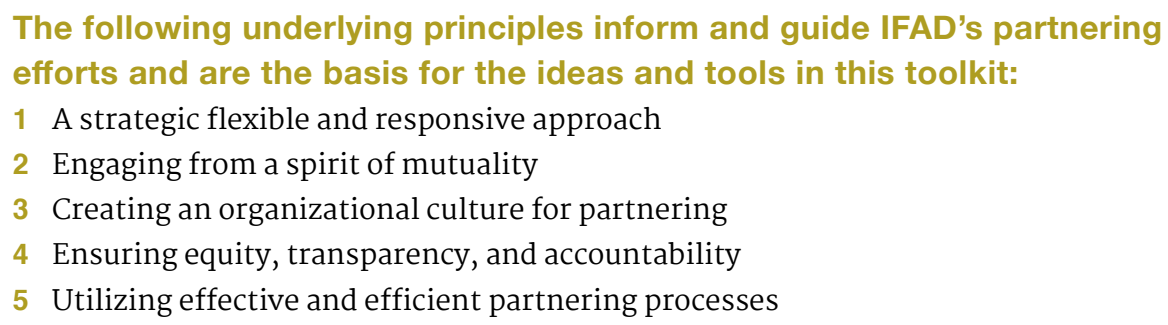

Delivering on IFAD's mission requires a wide diversity of partnerships at country, regional, and global levels. Partners include Member States, IFIs, United Nations agencies, multilateral agencies, research institutions, civil society organizations, private sector, multilateral platforms, and foundations (See TOOL 2 for further details).

Partnerships look and work differently at the different levels of IFAD's operations across projects, countries, regions, and global engagement, as well as within grants. The Toolkit provides support for partnering in all these aspects of IFAD's operations. 
The key elements of IFAD's Partnership Framework are summarized in the diagram below.

\section{IFAD's contribution to SDGs}

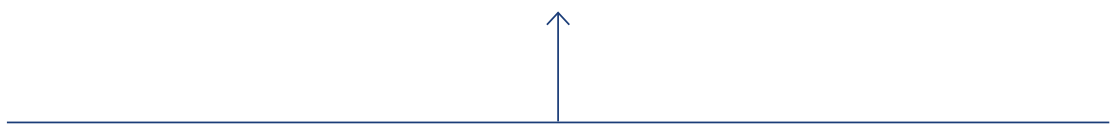

IFAD results and impact

\begin{tabular}{|l|}
\hline Partnership \\
monitoring \\
and reporting \\
\hline Partnership \\
indicators \\
and reporting \\
guidelines \\
\hline Embedding \\
monitoring in \\
ORMS and \\
GRIPS \\
\hline Capturing results \\
from country, \\
regional \\
and global \\
engagement \\
Reporting \\
on partnerships \\
and contribution \\
to IFAD results \\
\end{tabular}

- Greater economic mobillity through increased production and market access,

- Greater resilience and improved nutrition enabled by resource allocation,

- Resource utilization and transforming resources

\begin{tabular}{|c|c|c|}
\hline & Partnering outcomes & \\
\hline $\begin{array}{l}\text { 1. Country impact } \\
\text { at scale }\end{array}$ & $\begin{array}{l}\text { 2. Supportive enabling } \\
\text { environment }\end{array}$ & $\begin{array}{l}\text { 3. Capable and effective } \\
\text { partners }\end{array}$ \\
\hline
\end{tabular}

\section{Influencing policy and development agendas}

4. Knowledge generation and Innovation

\section{Partnering objectives}

2. Leveraging financial
resources

5. Strengthening private sector engagement

\section{Enablling coordinated country-led development}

6. Enhancing visibility
Underlying Partnering principles

1. Strategic flexible and responsible approach

2. Engaging from a spirit of mutuality

3. Creating an organizational culture for partnering

Integrating partnering in IFAD business processes

\begin{tabular}{l|l|l|l|l|l|}
$\begin{array}{l}\text { Strategy } \\
\text { develop- } \\
\text { ment }\end{array}$ & COSOPs & Projects & Grants & $\begin{array}{l}\text { Regional } \\
\text { engage- } \\
\text { ment }\end{array}$ & $\begin{array}{l}\text { Global } \\
\text { engage- } \\
\text { ment }\end{array}$ \\
\hline
\end{tabular}

\section{Partnering instruments and tools}

\begin{tabular}{l|l} 
Instruments: & Tools: \\
- MoUs & - Effective partnering criteria \\
- Membership of alliances and platforms & - Partnership scoping \\
- Financial agreements & - Fit-for-partnering assessment \\
- Grants & - Partnership agreements \\
- Contracts & - Partnership review (health check)
\end{tabular}

4. Ensuring equity, transparency and accountability

5. Utilizing effective and efficient partnering processes 


\section{Four phases of partnerships}

This toolkit uses a process model that reflects how IFAD partnerships typically develop. It has four phases: (1) Scoping and Selecting, where the opportunity for partnerships is clarified and assessed, leading the choice of the most suitable partners; (2) Setting Up, where agreements and preparations are made with the prospective partner; (3) Implementation, in which the partnership is structured and managed in order to optimize performance for results; and (4) Monitoring and Reviewing, in which information on the performance of partnerships is collected, analysed, and reported for the purposes of learning and accountability.

For each phase, the toolkit contains two tools that will help you to come to grips on your partnering process. They will guide you to ask the questions that are needed to make good decisions about the partnerships you are setting up or managing. There are also three cross-cutting tools that are relevant for all four phases.

Tool

Purpose of tool

\begin{tabular}{|c|c|c|}
\hline 1. Scoping and Selecting & 2 & $\begin{array}{l}\text { Identifying and prioritizing } \\
\text { partnerships }\end{array}$ \\
\hline$\downarrow$ & 3 & $\begin{array}{l}\text { Prospective partnership } \\
\text { assessment }\end{array}$ \\
\hline \multirow[t]{2}{*}{ 2. Setting Up } & 4 & $\begin{array}{l}\text { Negotiating and } \\
\text { documenting partnership } \\
\text { agreements }\end{array}$ \\
\hline & 5 & $\begin{array}{l}\text { IFAD mechanisms for } \\
\text { establishing partnerships }\end{array}$ \\
\hline \multirow[t]{2}{*}{ 3. Implementation } & 6 & $\begin{array}{l}\text { Effective partnership } \\
\text { management and } \\
\text { communication }\end{array}$ \\
\hline & 7 & $\begin{array}{l}\text { Tips for troubleshooting } \\
\text { partnerships }\end{array}$ \\
\hline 4. Monitoring and Reviewing & 8 & $\begin{array}{l}\text { Partnership } \\
\text { review }\end{array}$ \\
\hline
\end{tabular}

To better identify and prioritize IFAD partnerships on the country, regional, and global levels

To enable decisions about which prospective partners will best contribute to IFAD's objectives

To give an overview of the partnership instruments that IFAD uses, and to help you select what best fits your partnership needs

To guide you through the process of discussing and negotiating with a prospective partner, and to put your agreements on paper

To guide you in putting the right building blocks in place to implement partnerships effectively

To provide assistance for commonly encountered problems and conflicts in partnering

To guide you in conducting annual or other regular reviews of the partnership, in order to improve its performance and to maintain a shared understanding and commitment between partners

Monitoring and reporting on partnerships

Cross-cutting tools
Partnering with government
To help you set up M\&E processes with your partners and to report on partnerships in line with IFAD expectations and procedures

\section{Engaging Government}

To improve the quality of partnering with IFAD's partner country governments, and to understand the challenges of different country contexts
Engaging Private Sector
11 Engaging effectively in partnerships with the private sector
To provide guidance on the specific considerations for IFAD partnering with the private sector, including due diligence
Engaging with MSPs
Engaging effectively in complex multistakeholder partnerships
To assist you in understanding the opportunities and challenges of engaging in multistakeholder partnerships and in optimizing value for IFAD 


\section{Partnering in different areas of IFAD's work}

The tools are designed to support partnering in all aspects of IFAD's work across projects, country strategic opportunities plans, regional engagement, global engagement, and within grants. These partnerships include bilateral partnerships with single institutions, as well as engagement in multistakeholder networks and platforms (see TOOL 10). Partnering will have different considerations and priorities across these different areas.

\section{cosop}

Country strategic opportunities prgrogrammes (COSOPs) provide the basis for planning, managing, and monitoring country-level partnerships. COSOPs should identify the most strategic partners for leveraging finance, enhancing policy engagement, and ensuring effective delivery of the country strategy.

\section{Key considerations:}

- Ensure partnering considerations are fully integrated into the COSOP

- Specific guidance for partnerships can be found in the COSOP Guidelines (Operational Procedures and Guidelines for Country Strategies 2019) and its Appendix VIII on Strategic Partnerships.

- Be as explicit as possible in the COSOP about which key partnerships will contribute in what ways to delivering the country programme.

- Consider what partnerships are needed to deliver across the six partnering objectives.

- In line with the COSOP guidelines, ensure the effectiveness and benefits of country partnerships are monitored and reported.

\section{Country Projects}

County projects involve multiple partnerships to enable their implementation. Partnership with government and ministries is critical for delivery, and needs to be carefully considered and managed.

\section{Key considerations:}

- Project Concept Notes and the PDR should fully consider partners and partnering issues in line with the COSOP.

- Effective delivery of projects will depend on numerous partnerships, so ensure that project staff have the necessary partnering skills.

- The operations manual should describe how to ensure that partnerships work effectively and that the necessary capacities and monitoring are in place..

- Consider using TOOL 6 on partnering agreements to strengthen the foundation of project level partnerships.

- Ensure that the MTR and completion report adequately consider partnerships, in order to learn lessons and improve partnering effectiveness.

\section{Regional}

Partnerships on the regional level are important for IFAD, particularly in terms of resource mobilization, influencing policy, and creating visibility. IFAD's financing partners, including the World Bank and Regional Development Banks, will often operate on the regional level; coordination and engagement at this scale will therefore be needed. Both regional policy forums and regional governmental organizations influence national policy. To achieve IFAD's overall objectives, it will often be necessary to profile IFAD's work on the regional level in forums and with regional governmental, international, and civil society organizations. 


\section{Key considerations:}

- Regional partnering should be guided by a brief regional engagement strategy, to be developed by regional devisions, which identifies key partners and expected partnering outcomes.

- A brief annual note to cover partnership highlights, outcomes, and emerging issues should be produced and forwarded to GPR.

- The regional scale is often an important interface between country-level and global-level partnerships, and regional hubs should support communication in both directions.

- Regional partnership activity is largely supported through grants.

- The six partnership objectives are to be used as a checklist to select areas where partnerships may be needed and would add value to IFAD's operations on the regional level

\section{Global}

IFAD has a significant global presence, which is critical if it is to influence policy and development agendas, profile its relevance and impact, and mobilize resources. To optimize its partnering on the global level, IFAD needs to be selective and focused in the partnerships it engages with and in the outcomes it seeks. On the global level, IFAD is involved with numerous multistakeholder platforms and networks.

\section{Key considerations:}

- Partnering on the global level is to be guided by a global engagement strategy and an annual workplan developed and agreed on across the house.

- Global partnerships and engagements are coordinated by GPR, so liaising with the appropriate GPR staff on partnership development or issues is important.

- Engagement on the global level often depends on input from projects and countries, and staff at these levels, in particular, to make use of IFAD's field experience.

- IFAD often needs to put MoUs and partnership agreements in place on the global level to support implementation of partnerships on other levels.

\section{Grants}

Grants support much of IFAD's partnering on the country, regional, and global levels. There is a need to more clearly recognize and strengthen partnering within the grant process. The partnering phases and tools provide a clear approach for doing so.

\section{Key considerations:}

- The grant concept note should address how the grant will support partnerships between IFAD and the grant applicant.

- In many cases, grants are likely to be more effective if they are established as "partnerships" rather than as "contracts".

- The extent to which the grant will contribute to partnering should be a criterion for grant review.

- The design document should use the Criteria for Effective Partnering as a guide for grant design, assessment, grant management, and evaluation.

- For the purposes of the Monitoring and Review phase, corporate level reporting in GRIPS should also include details on the contribution of grants to IFAD partnerships.

\section{Where to go from here?}

The Checklist for effective partnering TOOL 1 familiarizes you with what is needed for an effective partnership. From there, you can consider other tools depending on where you are in the process of developing or supporting partnerships. 


\section{Checklist for effective partnerships}

\section{AIM OF THE TOOL}

To gain clarity on what is needed for an effective IFAD partnership at all

levels: project, country, regional, global, and in grants.

\section{WHEN TO USE IT}

When you are considering new partners or revising existing partnerships

during the Scoping and Selection phase-for example, when preparing a

COSOP, country project, or developing a regional Engagement Strategy

or Global Engagement strategy.
The Partnering Toolkit will assist you in developing partnerships that meet the criteria for effective partnering, summarised below. Use this list to familiarize yourself with what is needed for an effective partnership, or use it as a checklist when working with partners to ensure you have covered the most important elements in each of the partnering phases.

Worksheet 1.1: Checklist for effective partnerships

Phase

Partnership effectiveness element
Scoping and Selecting
1 There is a clear rationale and purpose for the partnership

2 The partnership will add clear value for both parties, given the costs of partnering

3 There are no significant reputational risks for either party

4 There is alignment on the underlying values, goals, and objectives of the partners

5 Clear tangible results from the partnership can be identified

Setting Up

Implementing

Monitoring

and Reviewing

Source: Appendix V of the Partnership Framework.

6 The partners have the time and financial resources to commit to delivering on the partnership resources

7 The partners have the capabilities - in the form of knowledge, skills, organizational structure, and experience - to deliver on the expected results

8 A partnership agreement is developed and signed

9 There is an action plan to guide delivery of the expected results

10 The partnership has the support of the people responsible or senior managers in the organization

11 The staff developing and managing the partnership understand and can apply the basic principles of good partnering

12 Specific staff are allocated as responsible people or as contact points for the partnership

13 There is regular open, honest communication between the partners about the progress of the partnership and any emerging issues

14 There are regular structured partnership reviews ("health checks") that assess the performance of the partnership against the partnership agreement and action plans

15 There is regular and transparent reporting on the partnership

Where to go from here?

TOOL 2 Identifying and prioritizing partnerships, will help you consider what type of partners IFAD might need for the best possible results. Depending on which elements scored 'No' or 'Partly' in worksheet 1.1, select relevant tools from the Overview to address the elements needing urgent attention. 


\section{Identifying and prioritizing partnerships}

AIM OF THE TOOL

To better identify and prioritize IFAD partnerships at all levels: project, country, regional, global, and in grants.

WHEN TO USE IT

When you are considering new partners or revising existing partnerships during the Scoping and Selection phase - for example, when preparing a COSOP, country project, or developing a regional or Global Engagement strategy.

\section{How this tool can help you}

This tool can help you to initially identify and prioritize the partnerships needed to deliver on IFAD goals and objectives. Clarity on what you want to achieve-your strategy - is the starting point, and needs to occur before the identification of partners. As IFAD already works with many partners, it will often be tempting to fall back on those partners with which you have a history. This tool encourages you to step back and undertake a wider stakeholder mapping, to make sure you are not missing partners who could potentially bring new resources, ideas, and innovation to your work. IFAD cannot work with everyone, so this tool also provides guidance on prioritizing those partners that are likely to be most strategic for achieving IFAD objectives.

Each COSOP, country project, grant, regional strategy, or global engagement plan will have its own specific objectives and results that need to be achieved. However, IFAD's six Partnering Objectives provide an overview of key areas where partnerships are likely to be needed and around which specific results can be identified.

This tool is the first step in scoping and selecting partners and then setting up the partnership. After identifying and prioritizing potential partners, you will need to do a more detailed assessment of each partner, which provides the basis for moving on to negotiating a partnership agreement.

In some cases, establishing the right partnerships for IFAD may be an iterative exercise. Having identified a potential partner, it may be that issues emerge during the partnership assessment or negotiation process, leading you to seek alternative partners.

All these tools are intended to be used flexibly and adapted to your needs. Depending on your situation and needs, you may choose to use the worksheets as a quick reminder of issues to consider, or you may opt to fill them out in detail.

\section{Key steps}

This tool takes you through four key steps. For some situations, it may be very obvious who you need to work with. In other cases - for example, when setting up a new country project or a new area of global engagement-it may be necessary to have a more rigorous process of identifying and prioritizing partners. In all cases, it will be valuable to check that you have given sufficient attention to each of these four steps:

1: Know
what you want to
achieve:
While this might seem
obvious, evaluation
of IFAD partnerships
suggests that quite
often partnerships are
established without
sufficient clarity about
the expected results,
and what will be needed
for these results to be
delivered.
Use the worksheet below
to review the six IFAD
Partnering Objectives, to
help clarify your partnering
needs and expectations.

2: Map stakeholders
to identify potential
partners:
Don't miss out on
potentially valuable
partners because they are
off your radar.

Use the table provided to do a quick scan of potential partners and for a preliminary assessment of suitability.

\begin{abstract}
3: Prioritize
your potential

partners:

IFAD has decided that

it needs to be more

focused on "strategic"

partners and to invest in

the effectiveness of these partnerships, rather than spreading its partnering efforts too thinly over too many partners.
\end{abstract}

Use the strategic partner assessment criteria to help prioritize the most critical partners for helping to achieving IFAD's development goals.
4: Develop an overview of key partners:

Provide an overview of key partners in relation to the IFAD Partnering Objectives.

\footnotetext{
Use the worksheet to provide a simple overview that can also support communication, monitoring, and follow up.
} 


\section{Step 1: know what you want to achieve}

IFAD design documents, whether for COSOPs, projects, grants, or regional and global engagement, should be as explicit as possible about the role of partnerships in achieving goals and objectives. The IFAD Partnering Objectives provide a guide to whether key areas for IFAD partnering have been considered.

The worksheet below provides a simple framework for identifying desired outcomes or results in relation to each IFAD Partnering Objective, and then assessing partnering requirements. How working with partners and other stakeholders will enable results to be achieved is a crucial aspect of any "theory of change", and should be the basis of the project and programme designs. The more clearly the theory of change articulates how IFAD will collaborate with partners and stakeholders, and the underlying assumptions including assessing staff costs for IFAD, the easier it will be to identify, priorities, and negotiate appropriate partnerships.

\author{
IFAD's six Partnering Objectives \\ 1 Influence policy and development agendas \\ 2 Leverage financial resources \\ 3 Enable coordinated country-led development processes \\ 4 Generate knowledge and innovation \\ 5 Strengthen private sector engagement \\ 6 Enhance visibility
}

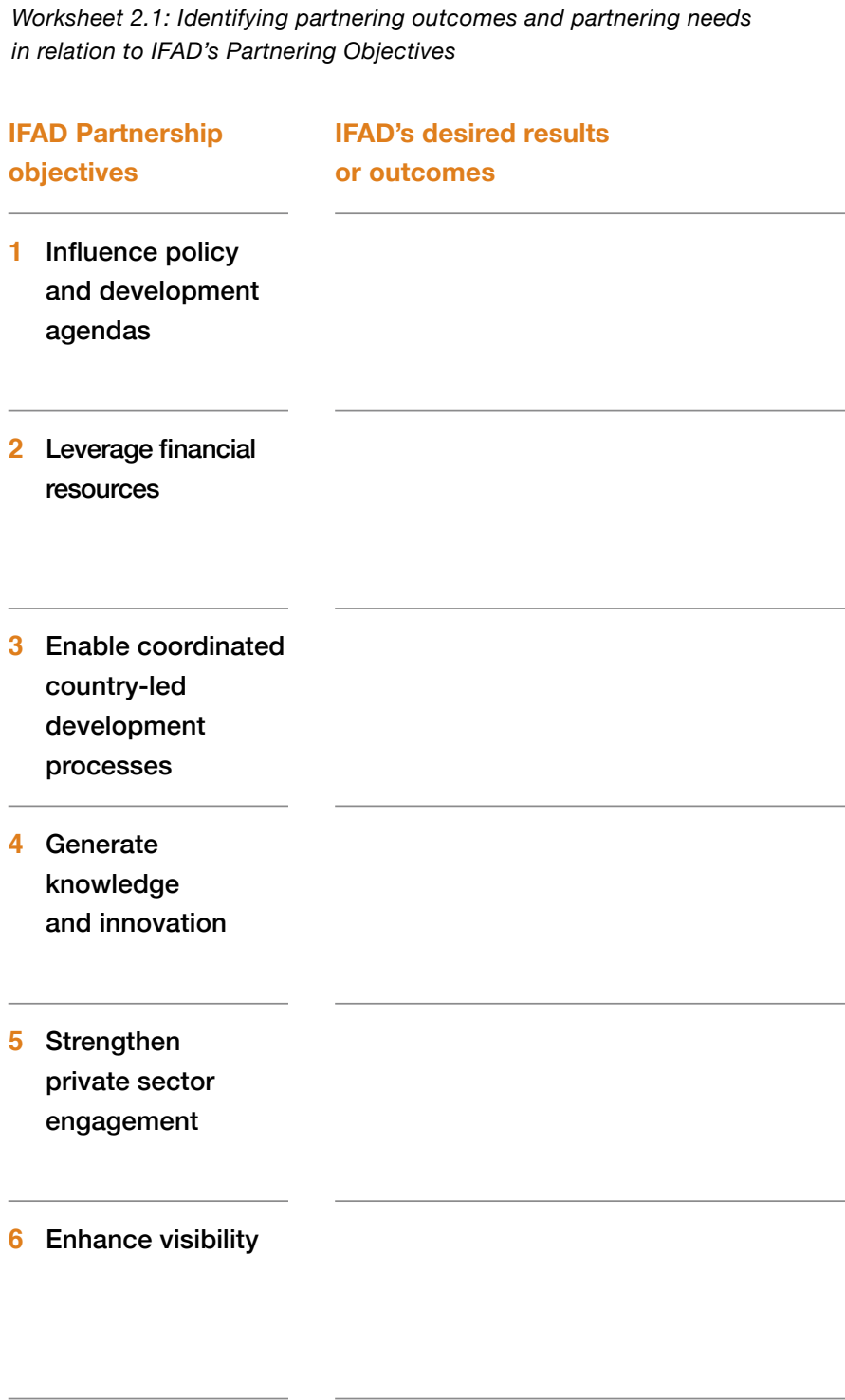

How does IFAD need to partner in order to achieve these results or outcomes?

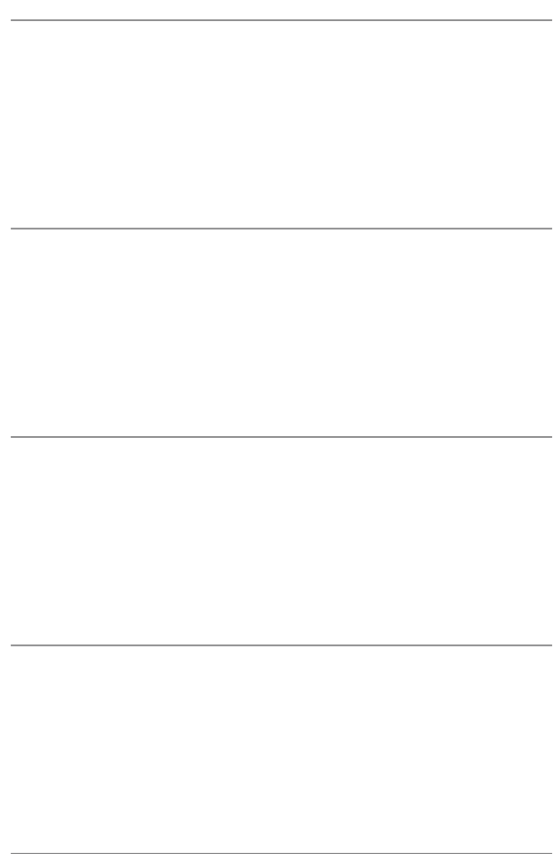




\section{Step 2: map stakeholders}

With your Partnering Objectives in mind, consider all the different stakeholders who could potentially be good partners. A stakeholder is anyone who can affect or be affected by an issue, whether positively or negatively. Stakeholder mapping will allow you to systematically identify all the interested or interesting stakeholders, and help you to get started on defining the potential roles that each of these might take up in the context of IFAD objectives. This will help you to make sure that no potentially valuable partners have been overlooked. Collecting information on partners can be time consuming. Do check if other Divisions already have a partnership in place. It is important to assess whether staff costs for IFAD weigh up against the benefits of partnership.

Example 2.2: Stakeholder mapping

\begin{tabular}{ll} 
Stakeholder & $\begin{array}{l}\text { Characteristics } \\
\text { (type of organization, size, } \\
\text { and mandate) }\end{array}$ \\
\hline $\begin{array}{l}\text { Regional } \\
\text { development }\end{array}$ & $\begin{array}{l}\text { A financial institution with } \\
\text { strong links to governments } \\
\text { in the region }\end{array}$
\end{tabular}

$\begin{array}{ll}\text { National } & \text { A membership organization } \\ \text { farmers' } & \text { with a strong reputation }\end{array}$

organization

\section{International} agribusiness

\section{Interests \\ (stake in partnership)}

Keen to partner on rural infrastructure that will support value chains in IFAD project

Wants support for a greater voice for farmers in national policy debates

\section{Wishes to improve its} reputation through greater engagement with smallscale farmers

\section{Influence and resources \\ (contributions to the partnership's successful outcome)}

Able to provide loans to government and some technical assistance

Has limited resources and would need to be supported by a grant

Possesses some resources for extension services; could pay farmers if included in value chain and could provide farmer financing

\section{Challenges \\ (e.g., limited decision- making power, staff costs weigh up to benefits, not informed)}

May be difficult to align timing of loans to be mutually beneficial

A recent change in
leadership due to internal
struggles means its future
capabilities are unclear
The reputation risk due to
land acquisitions means that
it is unclear whether the
operations side of the orga-
nization is as committed as
the CSR side
A large global corporation
with extensive markets and
strong country operations. 
Worksheet 2.2: Stakeholder mapping table.

Stakeholder

\section{Characteristics}

(What is the nature of the

stakeholder - type, size,

mandate, etc.?)

\section{Interests}

What are the key interests

of this stakeholder, and

how does this align or con-

flict with IFAD's interests?)
Influence and resources

(What influence or resourc-

es - financial, technical,

and human - would the

stakeholder bring to the

partnership?)
Challenges

What are the challenges

in working with partner, including alignment of interest/procedures; IFAD costs of delivering weigh up against benefits.) 


\section{Step 3: prioritize partners}

After you have become clear about your partnering strategy and have updated your overview of potential partners and their roles, the next step is to prioritize. You need to reflect carefully on which partnerships will be most critical to IFAD's success. The table below provides the criteria by which IFAD prioritizes partnerships.

For IFAD, strategic partnerships are those partnerships on the country, regional, or global levels that are most important to IFAD in achieving its objectives. Strategic partnerships make a significant contribution to increasing IFAD's scale of impact and influence. These partnerships need to be underpinned by strong mutual interests and good alignment of operating procedures if they are to succeed.

Across country, regional, and global levels, IFAD needs to identify the partnerships to which it will give the most attention in order to ensure that results are delivered. There is no specific number of strategic partners suggested, and the boundary between a strategic partner and a less strategic partner will inevitably be blurred. However, it is anticipated that it would be appropriate to identify about ten strategic partners on the country and regional levels. The number will be higher on the global level.

The worksheet below for prioritizing strategic partners can help you to compare the strengths or possible limitations of existing and potential partners. You can score each criterion as not applicable (NA) red, orange, or green, meaning weak, adequate, and strong, respectively. Strategic partners should score mostly green. If a partner is seen as very important to IFAD but is scoring red or orange, consider carefully what is needed to improve this in setting up the partnership.

Worksheet 2.3: Criteria for prioritizing partners

IFAD Criteria for prioritizing strategic partners

1 The partnership is essential for IFAD to deliver on its mission or country programme

2 The degree to which there are significant mutual benefits

3 Critical or very important to delivering on one or more of the six partnership objectives

4 Key to leveraging financing for IFAD investments

5 Has existing track record of successful partnering with IFAD

6 New partner with significant potential

7 Commitment and motivation to work with IFAD in a collaborative way

8 Linkages between the partner and other IFAD partners

9 There is compatibility between operational processes and modalities of working

10 Staff possess the capability and motivation to deliver on the partnership

Potential partner score

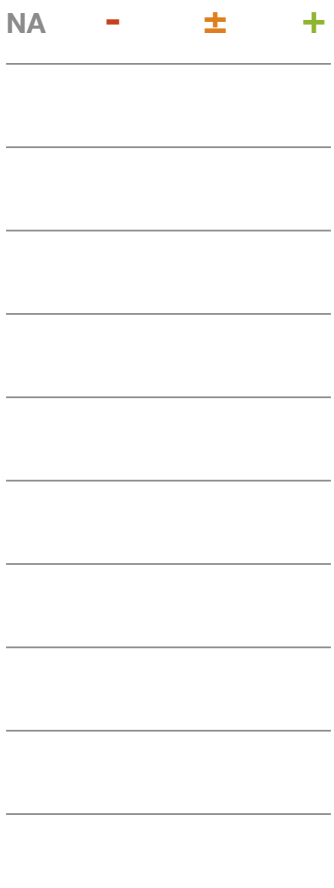

The point of identifying strategic partners is to direct limited resources (e.g. critical to assess staff costs) to those partnerships that will deliver the greatest impact for IFAD. This is not always straightforward. We are all aware that many priorities co-exist in IFAD, and nobody likes to do the unpopular work of pruning a portfolio. Yet, it is better to give a limited number of strategic partnerships the attention they need than to overburden IFAD teams with a large portfolio of partnerships that cannot be properly supported or monitored. This essential trade-off is about quality over quantity. 


\section{Step 4: provide a partnership overview}

The following table enables you to create an overview of proposed partners in your programme (COSOP, project, grant, or regional or global engagement strategy), in order to list the specific results and outcomes, and to summarize the justifications for partnering. It can also be found in the COSOP Guidelines Partnership Appendix.

Note that you may need to refine this overview as you move through the next phases, as the partners may change as you complete a more detailed partner assessment and begin negotiations with them. This table will also enable you to make a final check of your overall partner portfolio, and to assess whether you have the right balance to cover all necessary Partnering Objectives.

Worksheet 2.4: Potential partnership overview

Partnering

objectives

\section{Engaging in policy and influencing development agendas}

\section{Leveraging} financing

\section{Enabling coordinated country-led processes}

\section{Developing} and brokering knowledge and innovation (including SSTC)

Strengthening private sector engagement

Enhancing visibility

\section{Partners}

Names of key partners, networks, or platforms with which IFAD will work to achieve objectives. (If you put more than one partner in a box, keep track by giving each partner a number)
Specific results and outcomes from partnership

What specific results or outcomes, related to the COSOP, will be achieved through the partnership?
Justification for partnership What are the key justifications for working with this partner, network, or platform?
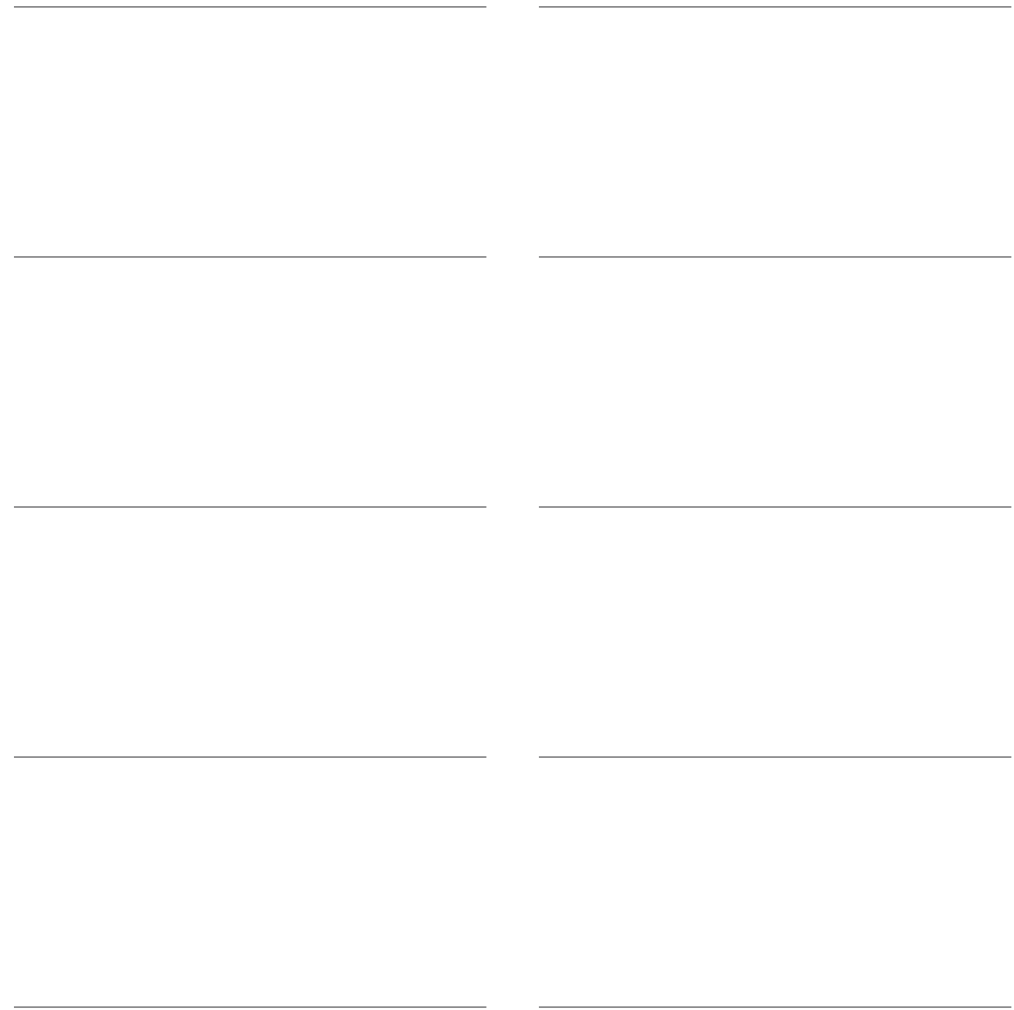
Example 2.4: Potential Partnership Overview. (This example shows how to complete the above table. Depending on the actual situation, the results and outcomes could be more specifically defined)

$\begin{array}{ll}\text { Partnering } & \text { Partners } \\ \text { objectives } & \text { Names of key partners, networks, or } \\ & \text { platforms with which IFAD will work to } \\ & \text { achieve objectives }\end{array}$

\section{Influencing National Agricultural Working Group} policy
Specific results and outcomes from

partnership What specific results or outcomes, related to the COSOP, will be achieved through the partnership?

Improved implementation of land tenure policy

Improved food safety procedures

Regional development bank

National farmers' organization

Leveraging Government
financing

Agribusiness X

Multilateral/bilateral development agency

International Financial Institution or Multilateral Development Bank

Ensure access to land and infrastructure of rural poor

Support a series of policy analysis papers with IFPRI to enhance advocacy capacity of the organization
Justification for partnership What are the key justifications for working with this partner, network, or platform?

Government is actively engaging with $\mathrm{AgWG}$ on this issue

The network has held a high-profile event on this topic with good private sector and government engagement

The regional development bank has a proactive programme on access to resources for marginalized communities

The organization has good links and respect from government, but lacks a rigorous analysis of the key issues
USD 100 million (based on the agreed regional targets for domestic cofinancing)

USD 5 million for initiative $\mathrm{Y}$ to link $\mathrm{x}$ number of farmers to the value chain

USD 10 million (based on the agreed regional targets for International cofinancing) for initiative $\mathrm{Y}$

USD30 million (based on the agreed regional targets for international cofinancing) for initiative $\mathrm{Y}$

Jointly financed support for agriculture statistics

Collaborative initiative on nutrition

Improved UNDAF monitoring

Develop coordination platform of civil society organizations
Actively engaged in value chains in project location and wishes to expand sources in collaboration; has strong track record of working with smallholders

Strong interest and commitment for working in partnership with IFAD

Strong alignment with in-country programmes

\section{Enabling coordinated country-led processes}

National Agricultural Working Group (AgWG)

Rome-based agencies (RBAs)
NGO platform $\mathrm{X}$
A key platform for coordinating donor activities that has strong government support and engagement

Linked to the AgWG, the RBAs have agreed to work on agriculture and nutrition

In collaboration with government major effort to improve data collection for indicators that will support results monitoring for IFAD projects

Platform is highly active and has created good links between field level NGOs and government 


$\begin{array}{ll}\text { Partnering } & \text { Partners } \\ \text { objectives } & \text { Names of key partners, networks, or } \\ & \text { platforms with which IFAD will work to } \\ & \text { achieve objectives }\end{array}$

\begin{tabular}{l}
$\begin{array}{l}\text { Developing } \\
\text { and brokering } \\
\text { knowledge } \\
\text { and innovation } \\
\text { (including } \\
\text { South-South } \\
\text { and Triangular } \\
\text { Cooperation) }\end{array}$ \\
\cline { 2 - 2 }
\end{tabular}

Project X

National Agricultural Research Centre (NARS), in collaboration with IFPRI

$\begin{array}{lll}\begin{array}{l}\text { Strengthening } \\ \text { private sector }\end{array} & \text { Agribusiness X } & \begin{array}{l}\text { Develop joint project on X's value } \\ \text { chain in project areas }\end{array}\end{array}$

engagement
Specific results and outcomes from partnership What specific results or outcomes, related to the COSOP, will be achieved through the partnership?

Support for survey on changing sources of household income

Develop innovative financing and ICT support mechanisms for women traders

Collaborate on an Uber-type model for machinery rental

Strengthen capacity of NARS for food system foresight

Justification for partnership What are the key justifications for working with this partner, network, or platform?

IFPRI is highly respected in the country, has started this work, which is critical for better understanding of IFAD project areas

NGO X has developed a successful pilot that has the potential to scale and has good links to private sector actors

Innovative new project funded by $\mathrm{X}$ that is showing good results and can be expanded to IFAD project areas

Promising initial work can be strengthened to help provide better long-term views on food market change

Agribusiness $\mathrm{X}$ has approached IFAD to work in partnership on several areas. The potential benefits seem high, the business is respected, and government is supportive

World Economic Forum country platform
Chamber of commerce
The chamber has a better understanding of key policy issues affecting smallholder commercialization and advocates for change
IFAD is to engage in the platform and participate in annual conference and contribute report on key factors for inclusive value chain development
The platform has high-level business and government participation. There is a need for business and government to better understand blended finance options for inclusive value chain development

The active chamber has not focused historically on agriculture, but has new leadership that sees this as important

Key development partners all participate along with government that IFAD's work is understood and profiled

IFAD participates and presents at key forums
Active national organization that holds high profile events with strong links to producer organizations in IFAD projects

\section{Where to go from here?}

TOOL 3 Prospective Partnership Assessment, will help you choose the best-fitting partner for your objective from this broad analysis of stakeholders and potential partners.

Looking at private sector partners? TOOL 11 provides tips on effectively engaging companies. TOOL 12 On partnering with government, has specific pointers on how to get the best out of IFAD's partnering work with government. 


\section{Prospective partnership assessment}

AIM OF THE TOOL

To assess the fit between IFAD

and a potential partner, and to

understand the potential partner's

strengths and limitations prior to

taking the decision to partner.

WHEN TO USE IT

During the Scoping and Selecting

phase to help you select partners

with the best strategic fit, whether

on the project, COSOP, grant,

regional, or global level.

\section{How this tool can help you}

This tool can help you assess the fit between IFAD and a partner, and to verify that the partner has the capabilities and profile needed to meet the ambitions of the potential partnership. This also needs to involve an assessment of any potential reputation risks or conflicts of interest.

You should already have used TOOL 2 to identify IFAD's partnership needs and to create a list of potential partners. This stage is about doing your partnering homework before entering into negotiations with the potential partner (TOOL 4).

Remember that a good partnership is about the fit between the two parties, not just about what the partner brings. For any potential partner, it is important to understand IFAD's own internal realities and where these create strengths or possible constraints on a partnership, from both IFAD's perspective and that of the potential partner. For example, IFAD has had cases where the attempt to align funding procedures and procurement mechanisms in a timely manner has proved difficult.

The first part of this tool assesses the fit between IFAD and the potential partner, while the second part looks in more detail at the characteristics of the potential partner. You will need similar information and data on your potential partner for both parts of the assessment. Some of this may be public knowledge; however, you may also need to approach the partner for some of the information needed to make a good assessment.

Is there a good fit between IFAD and the potential partner?

A good partnership for IFAD needs to be complementary and workable across three domains:

1) The programme - what the partners want to achieve together

- Common vision and shared set of values for development

- Compatible theory of change for how the organizations believe their interventions will lead to change

- Agreement on the objectives or results to be achieved

- Complementarity of financial, human, and technical resources

2) Internal systems and structures - how the organizations function

- Legal and governance mechanisms enable a partnership to be formed

- Speed of decision-making and contracting aligns (often an issue with private sector actors)

- Procurement requirements are compatible

- Safeguarding requirements align

- Staff responsible for the partnership have sufficient decision-making authority to effectively manage the partnership

3) External relations - how the organizations profile themselves and relate to others

- Being in partnership with the other is good for the public profile of both and has no reputational risks

- The partnership strengthens wider networks for both parties

- The way the IFAD and the partner publicly profile themselves and their work is compatible

- The partnership would not be in conflict with or disrupt other important partnerships 


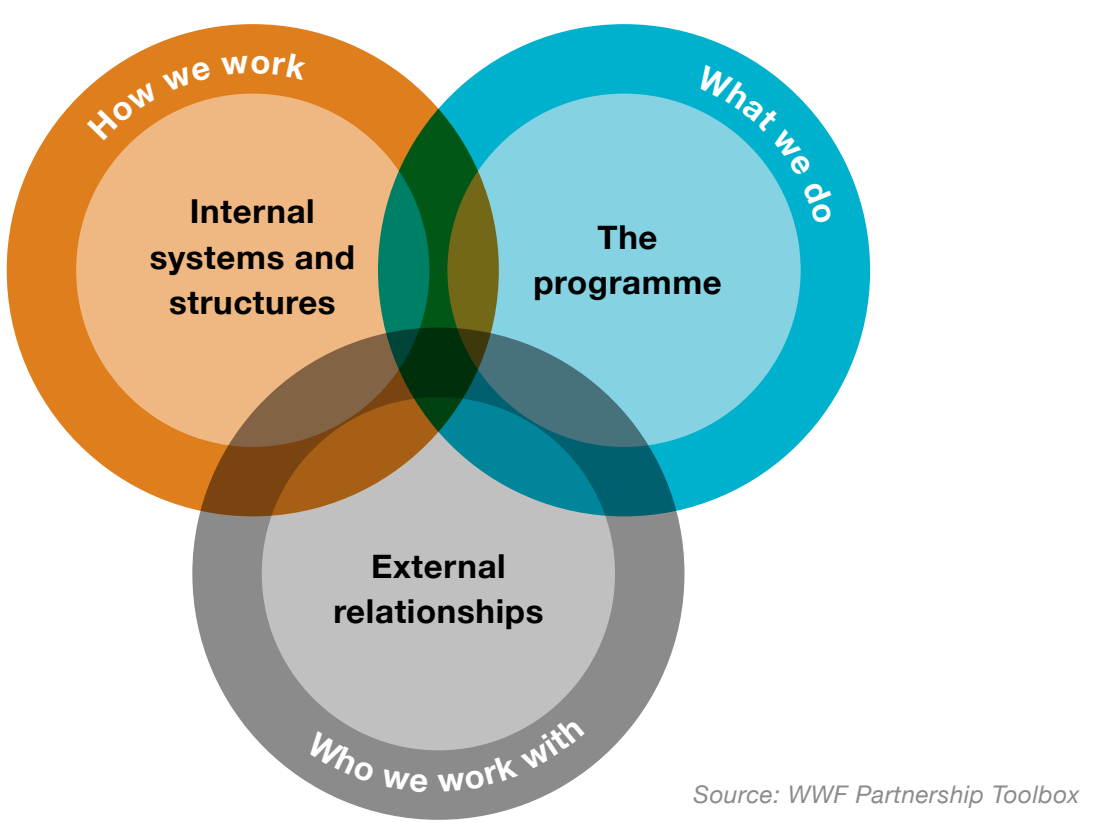

Below is a simple worksheet to help you quickly check on a partnering fit. If all three answers are positive, it is likely that IFAD and the partner will be able to work well together. The sweet spot is where all three dimensions overlap.

Worksheet 3.1 Checking the fit between IFAD and the potential partner (use the list of factors above when assessing your response)

\section{IFAD reality (circle)}

The programme

Are our goals, objectives, values, and theories of change sufficiently aligned?

Internal systems and structures

Is the way our internal systems and structures function compatible?

\section{Response}

Issues and how they might be resolved

- \pm+

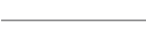

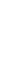

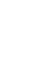




\section{Prospective partner realities: is this partner good for us?}

If you have concluded that IFAD and the prospective partner would be a good fit and could likely work well together, the next step is to carry out a more detailed final assessment of the suitability of the partner for IFAD.

The worksheet below is for internal use, to assess the value, risks, and implications of partnering with this particular organization. However, issues that emerge may require engagement with the prospective partner, either as part of this assessment process or during the next phase of setting up the partnership.

Worksheet 3.2 Partner assessment

Prospective partner:

1. The operational capacities of the prospective partner are adequate for the proposed role or mandate

2. The administrative and financial capacities of the prospective partner are adequate for the proposed role or mandate

3. The track record of the prospective partner is good from the point of view of IFAD's partnering needs

4. The prospective partner's skills and capacities are complementary with IFAD's

5. The prospective partner's governance structures are adequate

6. The reputational risks for IFAD are sufficiently low or well mitigated

7. Senior management buy-in has been secured for the partnership

8. The prospective partner's key staff are capable, good communicators and team players

The partnership itself:

9. The partnership provides significant

10. The costs are acceptable in relation
Not acceptable Perhaps acceptable (with adjustments) Acceptable Insufficient information

Implications/considerations/extra information needed
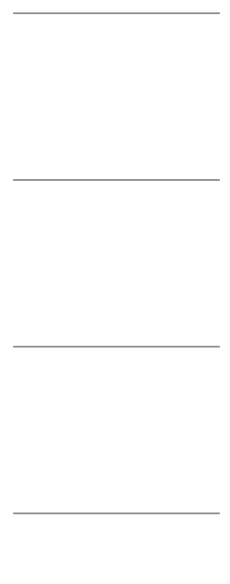

$\square \square \square \square$

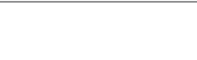

$\square \square \square \square$ to the value gained

\begin{abstract}
value and impact
\end{abstract}
Overall conclusion

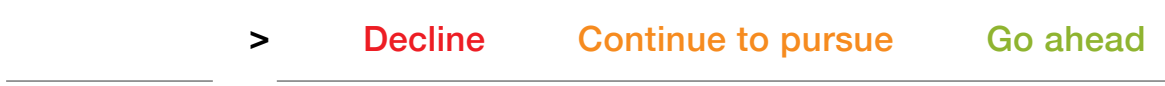


Here is an example of the tool in use:

Prospective partner: Horti Inc.

1. The operational capacities of the prospective partner are adequate for the proposed role or mandate

2. The administrative and financial capacities of the prospective partner are adequate for the proposed role or mandate

3. The track record of the prospective partner is good from the point of view of IFAD's partnering needs

4. The prospective partner's skills and capacities are complementary with IFAD's

5. The prospective partner's governance structures are adequate

6. The reputational risks for IFAD are sufficiently low or well mitigated

7. Senior management buy-in has been secured for the partnership

8. The prospective partner's key staff are capable, good communicators and team players

\section{The partnership itself:}

9. The partnership provides significant value and impact

10. The costs are acceptable in relation to the value gained

Overall conclusion

\section{Extra information needed}

The company has a good reputation in districts $\mathrm{X}$ and $\mathrm{Y}$. We are not sure how well-represented the company is in district $Z$, which is central to our COSOP.

Use the IFAD due-diligence procedure.

Horti, Inc. has only been active in this country for two years. We need to verify its track record in neighbouring and similar countries.

Horti, Inc. offers agri-input services which neither IFAD nor the government can offer.

There has been a recent significant change in the circumstances of Horti, Inc., because of a corporate restructuring. We need a status update on its new governance arrangement.

There is no unacceptable risk in this country, but we need to check with IFAD regionally and globally if this perception is shared.

No issues.

So far very good, but a key staff change is expected in near future. We need to ensure a good handover and check level of support from the new person.

The company's distribution network would allow for rapid scaling of innovations generated by the project. It's still unclear what the value proposition would look like.

Hard to say. We should ask colleagues if they have experience with measuring the cost-effectiveness of similar partnership

Decline $\boldsymbol{V}$ Continue to pursue $\square$ Go ahead

\section{Go/no-go checklist}

If your conclusions from the partner fit (worksheet 3.1) and prospective partner assessment (worksheet 3.2) are both positive, this means that it is worth investing IFAD resources in moving forward with the partnership. Remember, this is not a science: these assessments are enablers for frank conversation among key players on both senior and operational levels.

Where to go from here?

No go? Perhaps one of the other parties you have identified using TOOL 2: Identifying and prioritizing partnerships, could be a better fit. If the prospective partner is a private enterprise, make sure to use TOOL 11 to check the specific requirements, including due diligence, which IFAD has in place to enable partnering with private sector. If you are ready to move on and find out how your partnership needs to be structured,TOOL 4 shows you how to Negotiate and document a partnership agreement. TOOL 5 will introduce you to various IFAD instruments for partnering. 


\section{Negotiating and documenting a partnership agreement}

\section{AIM OF THE TOOL}

To guide you through the process

of negotiating, agreeing on, and

documenting a prospective part-

nership.

\section{WHEN TO USE IT}

During the Setting Up phase, when there is an in-principle agreement to partner on both sides and it has become necessary to be more specific about what will be jointly achieved and how the partnership will function.

\section{How this tool can help you}

This Tool gives tips on how to develop a partnership agreement, and provides a template that covers the most important aspects to consider.

The partnership agreement template can be used flexibly in a range of ways. It could be used informally as a checklist of aspects to discuss when beginning to work with a partner. It could be used to develop a negotiated, written, and signed partnership agreement. This may complement, for example, a grant agreement or project-level contract. Alternatively, the template can be used as a guide to aspects to consider when developing contracts and MoUs related to partnerships. It could also be used to help clarify expectations and working arrangements with different government departments or units when implementing a country project.

\section{What is a partnership agreement?}

A partnership agreement creates a shared understanding between partners of why they want to partner, what they would like to achieve together, and how they need to work together for this to be realized.

Good partnering agreements will include the "softer" aspects of partnerships, such as underlying values, governance arrangements, communications mechanisms, and processes for dispute resolution, which are generally not well covered in contracts or Memoranda of Understanding (MoUs). A documented partnership agreement can be a valuable complement to the legally binding aspects of a partnership covered in contracts or MoUs.

Ensure partnerships are set up to deliver results

In setting up partnerships, give attention to what is needed to make them succeed and deliver results. Rushing to develop an MoU may not be the best initial path. Organisations are often keen to develop MoUs; however IFAD's experience is that, on their own, these often do not lead to resultsoriented partnerships. Instead, focus on identifying the results to be achieved and the actions and resources needed. It may be better to operate informally in the initial period, with a focus on developing an action plan, to see if there is sufficient momentum and commitment before moving to formalising the partnership.
There are a range of ways IFAD can establish a partnership, including written agreements and the use of funding mechanisms.

These are outlined in TOOL 5. This tool complements these IFAD processes. A key message is not to rush into developing MoUs with a partner until there is clarity on what will be achieved and confidence that the partnership will work.

The process of developing the partnering agreement is as important as what is put on paper. Developing the agreement is key to building relationships, creating trust, and clarifying expectations. The intent of a partnering agreement is to forge the foundations for partners to work together in a mutually supportive, respectful, open, and honest way. Partnering agreements help to avoid conflicts during implementation and the need to take recourse to legal mechanisms for dispute resolution. 


\section{Focus on three guiding questions}

One simple rule to ensure partners work effectively together is to be clear on the WHY, WHAT, and HOW of partnering. In setting up your partnership, focus on the following questions.

\section{WHY?}

\section{WHY do we want to partner?}

It is important to understand how the overall objectives of IFAD and the potential partner align in terms of visions for development, organizational goals, and underlying values. It is also important to understand how IFAD and the partner can complement each other in resources, capacities, expertise, and profiles. There does not need to be a perfect fit; however, understanding at the outset where there is a good fit and where there may be differences or potential tensions will help the partnering process. Some of this analysis will have already been carried out during the Scoping and Selecting phase (See TOOLS 2 and 3). However, it is important to be explicit about these aspects with your prospective partner.

\section{WHAT?}

\section{WHAT do we want to achieve?}

It is common sense, but partnerships need to be as clear as possible about what will be achieved together. Organizations with common visions and objectives my feel it is a "nice idea" to work together, but if this is not translated into clear objectives and action plans, little may result. Being explicit about what will be achieved together is the basis for being able to negotiate how the partnership will operate and who will contribute what.

\section{HOW?}

HOW do we need to work together to achieve our shared objectives?

This describes the details of how the partners will work together to achieve the results intended, and to ensure a good spirit of collaboration. It includes issues of resource input, governance, decisionmaking, planning and communication processes, agreements over branding, and how the work of the partnership will be externally profiled. 


\section{Follow the principles for effective partnering}

Right from the start, consider the principles of partnering needed for an effective partnership. The negotiating phase is a critical time to lay the basis for good relations. In the Partnership Framework, IFAD has defined Five Partnering Principles. Below, you will find some pointers to put these in practice to improve the quality of IFAD's partnerships.

\section{IFAD Partnering Principles}

\section{Engage from a spirit of mutuality} Both parties should be able to benefit from the partnership and feel that their needs, issues, and perspectives are being respected by the other.

2. Have a strategic, flexible, responsive approach Be clear on the overall goals of the partnership and recognize that circumstances may change, so be responsive to emerging opportunities and problems. Don't tie the partnership up in inflexible contracts.

3. Create an organizational culture for partnering Make organizational processes flexible enough to work collaboratively with others, develop staff "soft skill" capabilities for good partner engagement, and ensure management support

4. Ensure equity, transparency, and accountability Make sure that checks and balances are in place, and are adhered to, so that partnering choices are made in an inclusive and transparent manner.

5. Utilize effective and efficient partnering processes

Recognize that partnering is shaped by the practices of many staff across many organisational departments, and that this requires continuous optimization, coordination, and capacity development.
Implications for negotiating your partnership

- Step into the shoes of your partner to deeply understand their perspective.

- Be explicit and open about what each partner wants from the partnership in terms of resources, profile, and access to knowledge and expertise.

- Be visionary about what the partnership could deliver both parties.

- Explore carefully what strategies are needed for the partnership to deliver for both parties.

- Assess potential risks for the partnership and agree how to respond if they occur.

- Discuss how organizational processes - such as who makes decisions, procurement, and reporting requirements - might impact on the partnership, and consider how to respond.

- Engage leadership or management in the negotiating process

- Have a plan for staff training and capacity development in partnering

- Take care that the power, influence, or funding of an organization like IFAD does not inadvertently coerce an organization into a partnership that they feel is not equitable.

- Ensure that the reasons for partnering, funding arrangements, and decisionmaking are fully transparent.

- Make sure there are monitoring and feedback mechanisms that help to hold partners accountable to each other.

- Use the tools, guidelines, and tips in this Toolkit to optimize your partnering process 


\section{Develop a clear negotiation process}

Think through the process and time you will need to negotiate and agree on the partnership. A little more effort and attention to detail in the Setting Up phase can pay significant dividends later on in terms of the effectiveness of the partnership, and in avoiding destructive misunderstandings. The time you need will depend on how well you know your potential partner and your history of working together.

\section{IFAD internal steps for negotiating a partnership}

Step 1: Origination of Partnerships - When a partnership opportunity is identified, the originator shall contact GPR and LEG for their advice on whether an agreement is required and, if so, on what is the most appropriate type.

Step 2: Due Diligence - For any new partnership it is advisable that the originator undertakes a due diligence assessment of the partner.

Step 3: Developing and Negotiating an Agreement - The originating divisions normally lead the substantive negotiation of the agreement with support from LEG and GPR in drafting the agreement. While IFAD and the partner work towards agreement on a draft text, they will often need to seek internal clearance of the draft agreement from their respective authorities (i.e. Director GPR/LEG/originating div).

Step 4: Clearance and Approval - Done through a Decision Memo to be submitted by the Director of the originating division with clearance from LEG, GPR and other concerned divisions.

Step 5: Signature - IFAD and the partner will agree on the modality of signing (together in person, by mail, or via corporate digital signature solution). IFAD or the partner signs the two copies first and sends these to the partner for countersignature.
A helpful structure for negotiating the partnership can be to work through the WHY, WHAT, and HOW questions above. The partnership agreement template below also follows this flow and can be used as a guide to your discussions and negotiations.

Remember that the purpose of the negotiation process is not just to reach a written agreement. Creating understanding between the partners, and building relationships and trust, is just as important, and is critical to the longer-term management of the partnership. As much as possible, try to involve both the managers of the partner organization and those who will be involved in delivering on the partnership in the negotiation process

You may choose to have a series of meetings or to work through the negotiation in a single workshop. In general, it will be better to develop the partnership agreement over a longer time frame so that ideas and agreements can be checked and considered by each partner.

\section{Use the partnership agreement template}

The template below covers elements to consider in your negotiations and partnership agreement, and in drawing up the associated contracts, grant agreements, letters of agreement, or MoUs.

You can use this as a checklist or as a basis for structuring a written agreement. This is a comprehensive list, so you may not need to cover all aspects. Use the right column to tick off those elements that you think need to be included. 
Worksheet 4.1: Topics and guiding questions for developing a Partnership Agreement

Topics for

Partnership

Agreement

Guiding

Questions

Parties to the Organizations What are the organizations in the partnership?

Agreement

(Duplicate for number of parties)

Status What is their legal status?

Signing Representative Who is the responsible representative?

Contact person Who are the main contacts?

Rationale for Partnership

Focus What is the issue, problem, or opportunity that brings the partners together?

Vision What is the vision for change that each of the partners have, and how do these align?

Values What are the underlying values of the partners and how do these align?

Complementarity How do the partners complement each other and contribute to the focus of the partnership?

Intent

Objectives What will the partnership achieve? Being as specific as possible about objectives and results.

Milestones What will be key milestones of the partnership?

Work plan Which main activities will be undertaken by whom, and when?

Resources Financial What financial resources will be contributed by each partner, under what conditions?

Expertise What expertise will each partner contribute to the partnership

Personnel What human resources will the partners commit to the partnership?

Governance Partnership structure How is the partnership to be structured, and what if any legal arrangements will underpin it?

Decision-making How will decisions be made on behalf of the partnership, and by who?

Roles and responsibilities What will be the key roles and responsibilities of each partner?

Financial management How will the financial management of the partnership be organized?

Safeguarding How will the safeguarding requirements of partner organizations be met?

Communi- Internal What processes, meetings, and mechanisms will be put in place to ensure regular and effective cation

Include in negotiation/ agreement 
Topics for

Partnership

Agreement

Contingencies
Include in negotiation/ agreement
Guiding

Questions

Risks What risks to the partnership and its work do the partners see, and how would they like these to be mitigated?

Changes What is the scope for changing aspects of the partnership, and how will these be negotiated?

Dispute Resolution How will any problems or conflicts in the partnership be communicated and resolved, and who will have responsibility for dealing with dispute resolution on both sides of the partnership?

Dissolution What could lead to the dissolution of the partnership, and how would this be managed?

Formalities

Property rights How will intellectual or other property rights be managed within the partnership?

Confidentiality Are there any issues of confidentiality that need to be agreed upon?

Conflicts of interest Are there any existing or potential conflicts of interest, and how will these be managed?

Due diligence What due diligence processes need to be undertaken, and what is the outcome of these?

Limits and exclusivity What are the limits of the partnership agreement, and does it imply any exclusivity to the partnership?

Monitoring and Review

Notes and thoughts for developing a Partnership Agreement.
Success Criteria What are the specific agreed criteria or results against which the success of the partnership and the contribution of partners will be monitored and assessed?

Monitoring Plan What procedures and mechanisms will be put in place to monitor the results of the partnership and the effectiveness of the partnering process?

Health Checks What will be the processes and timing for regularly assessing and discussing the health of the partnership?

Based on your review of the topics and questions above, what are the implications for your Partnership Agreement?

Where to go from here?

Next in the sequence is TOOL 5, which introduces details of specific IFAD mechanisms for establishing partnerships. The Toolkit them moves onto the aspects of management and communication that should be considered during implementation. 


\section{IFAD mechanisms for establishing partnerships}

AIM OF THE TOOL

To provide an overview of the

mechanisms IFAD uses to

establish partnerships, and the

associated procedures.

WHEN TO USE IT

During the Setting Up phase,

when you need to understand the

ways in which IFAD can establish

partnerships and the procedures

for doing so. This may be when

you are first thinking about a part-

nership or when you are negotiat-

ing a partnership agreement.

\section{How this tool can help you}

This tool will help you understand the IFAD procedures for establishing a partnership. It outlines different types of agreements, ranging from informal to formal, and how these may link with funding arrangements.

\section{Use this tool in conjunction with Tool 4 Negotiating and Documenting a}

Partnership Agreement to ensure there are clear agreements between IFAD and the partner about the expectations, the nature of the partnership, and that the resources in place to be able to deliver on expectations. For a more detailed step by step guidance on partnership agreements please consult the Technical Guidance Note on Partnership Agreements .

In setting up a partnership, you need to be clear on how the IFAD instruments can be used and integrated. This tool provides you with an overview, and outlines the procedures to be followed.

There are two aspects to establishing IFAD partnerships:

1) agreements and 2) funding arrangements. Most IFAD partnerships are linked to IFAD funding mechanisms that are related to the loan or grant portfolios. However, this is not always the case, for example in IFAD's engagement in country, regional, or global level forums and networks. Partnership agreements establish the basis for a funding arrangement or specify the partnership expectations that may be implicit in a funding agreement. IFAD has different types of agreements that range from informal understandings to Letters of Intent and formalized Memorandums of Understandings (MoUs), agreed to by the IFAD Board.

For a partnership to function, there needs to be clarity of expectations and resources for it to deliver, so agreements and funding arrangements need to go hand in hand. This has not always been the case in IFAD. Funding agreements have been established, for example through grants, where a partnership is implicit with the grantee, but there is no clear agreement on partnering. Alternatively, MoUs have been established with insufficient attention to the resources needed for them to be operationalized.

Partnership agreements may set the context for funding arrangements, as for example with the MoUs that IFAD has with international financial institutions. Funding arrangements mostly have an associated contract. Contracts specify legal obligations between parties and are transactional. However, these generally do not cover the "softer" aspects of the partnership relationship that are needed for effective partnering. It is often worthwhile to complement contracts with some form of additional partnership agreement. 


\section{Types of agreements}

The table below describes ways in which IFAD may enter into an agreement with a partner. They are not mutually exclusive.

Agreement Types

Informal verbal or written agreement

\section{Action plan}

\section{Letters of Intent}

Memberships

Partnerships through financing agreements, grant agreement, or contracts

\section{Description}

This is the least formalized. For example, at a country level, IFAD may agree to partner with a famers' organization around a particular policy issue, or to hold an event. This partnering may be verbal or could be backed up with correspondence agreeing to the collaboration. There is no legal obligation, and the partnering is based on trust and good will. Informal arrangements can be a way of starting out a partnership without the need to initially formalize agreements.

IFAD can develop a joint action plan with a partner, outlining what IFAD and the partner intend to do to achieve a common objective. An action plan may be linked to an informal agreement or may underpin the more formalized agreements below. Working on an action plan can be a good starting point before considering a formalized agreement.

These are an IFAD instruments signed by Heads of Department that more formally establish the intention of IFAD and a partner to work together in a particular way to achieve particular objectives. They should generally be backed up by an action plan and have clearly identified partnering results. They are not legally binding. (The internal processes for Letters of Intent are described below.)

IFAD is a member of numerous platforms and networks. Such membership is by default a form of partnering agreement. As such, IFAD should carefully consider what will be achieved by engaging in the platform or network, and might consider negotiating with the organizers the conditions of IFAD's participation.

Financing agreements, grant agreements, and contracts will also often implicitly involve partnership alongside the contractual agreement. For example, the most important partnership for IFAD are those with partner countries. Grant agreements often underpin IFAD partnerships-such as long-term engagement with the CGIAR system. As these are legal agreements, it may be worth complementing them with non-legally binding partnering agreement based on the template in TOOL 5. Alternatively, key elements of the partnering agreement template could be embedded into these types of legal agreements or contracts or their supporting documents.

MoUs are the most formal instrument IFAD uses to engage in partnerships, and need to be approved by either the Board or the President. (The internal processes for MoUs are provided below.) 


\section{IFAD funding mechanisms to support partnerships}

Partnerships require resources from both sides if they are to achieve their results. As a financial institution, IFAD is often in the position of establishing partnerships where it provides financial resources and the partner provides the expertise, organizational setup, and human capabilities. Financial support mechanisms are thus critical to IFAD's ability to effectively partner. There are four main financing mechanisms, described below.

Funding instrument

Financing agreements

Grants

Co-financing

Project implementation contracts

\section{Description}

These are the mechanisms through which IFAD makes loans to countries, and establishes development partnerships with countries. Good partnerships with country governments and their ministries are critical, so it is important to think through the communication, as well as the other forms of agreements and planning that complement the financing agreement, in order to ensure a good basis for partnering.

Many of the partnerships that IFAD has with, for example, civil society, farmers' organizations, networks, and research bodies are based on grants. Consequently, it is important to consider how to develop a grant in ways that support a spirit of partnership, rather that is being seen as purely a mechanism of funding.

IFAD often enters into partnerships with other financial institutions and funding bodies. IFAD's 2018 cofinancing strategy defines cofinancing as: "financing from any source in support of - and in association with - an IFAD-funded project or programme. Cofinancing covers, but is not limited to, financing provided by governments (defined by some institutions as counterpart funding), beneficiaries, multilateral and bilateral development partners, the private sector and foundations. It can take the form of both cash and inkind contributions." The key sources of international cofinancing come from international financial institutions (IFIs), multilateral or intergovernmental sources (climate funds, OFID, EU), bilateral donors, other UN agencies and foundations/private sector. IFAD has an overarching framework, partnership agreements or MOUs with cofinanciers which govern the broad principles of engagement.

These are the contracts between an IFAD support country project and those who are engaged to help its implementation. These may be local NGOs or CBOs, producer organisations, businesses or consultants. In many cases these relationships will be of a partnership nature and will need to be managed as such.

\section{IFAD internal communications and partnership guidance}

GPR can provide you with additional support and guidance on partnering. When considering a new potential partner, is important to check whether IFAD has already had any partnership arrangements with them. Presently IFAD has MoUs with 93 Member States and organizations. With international organizations, it is important to check relationships with IFAD on the country, regional, and global levels. 


\title{
IFAD processes for Letters of Intent and MoUs
}

\author{
Table 2: Differences between Letters of Intent and Memoranda of Understanding
}

\section{Characteristic}

Legal

significance

\section{Letter of Intent}

Does not create any legal commitments.

\section{Content}

Timing

Approva

Clearances

Signature
A general expression of intent to work together that identifies potential areas of collaboration. It confirms the interest of the organizations to develop a partnership, but does not make specific commitments.

May or may not be time-bound. Shorter duration

By the Vice-President (if cross-departmental), or Head of Department.

LEG clears the legal aspects of the agreement.

GPR confirms alignment with IFAD's partnership framework priorities, and ensures best practices are incorporated, such as clear goals, results, clear mechanisms for engagement, and reporting for results.

The relevant Head of Department, or the VicePresident (if cross departmental), have the authority to sign Letters of Intent.

\section{Memorandum of Understanding}

Expresses a convergence of will between the parties, indicating an intended common line of action. Whether a document constitutes a binding contract depends only on the presence or absence of welldefined legal elements in the text of the document. The required elements are: offer and acceptance, consideration, and the intention to be legally bound.

Describes objectives, areas and modes of cooperation, timeline, responsibilities, communication, and visibility and intellectual property, as well as other legal provisions as necessary.

May or may not be time-bound, though it is good practice to have it time-bound. In this case, the period is generally taken to be three to five years renewable. It is suggested to always define in the agreement the period of implementation.

- By the Executive Board, as per Article 8.2 of the Agreement Establishing IFAD.

- The President can approve MoUs with Member States and their organization.

- The relevant Head of Department, or the Vice-President (if cross departmental), have the authority to approve MoUs with organizations with which IFAD already has a Cooperation Agreement.

LEG clears the legal aspects of the agreement.

GPR confirms alignment with IFAD's partnership framework priorities, and ensures best practices are incorporated, such as clear goals, results, time limits, clear mechanisms for engagement, and reporting for results.

- $A \cup O$ to be inserted, in case there are any anti-corruption provisions.

- PMD, if activities are expected to take place in a regional division.

- SKD, if activities are expected to take place in PMI, ECG, or RIA.

- COM clears any aspects of the agreement relating to communications and visibility.

- The President has authority to sign Cooperation Agreements approved by the EB.

- The relevant Head of Department, or the Vice-President (if cross departmental), have the authority to sign MoUs with organizations with which IFAD already has a Cooperation Agreement. 


\section{Signing the agreement}

\section{Finalisation}

- When IFAD and the partner reach an agreement on a draft text, they both need to seek internal clearance for the agreement from their respective authorities. In IFAD, this is the Director of Originating Division and the Directors of GPR and LEG. This may lead to proposed changes, which will need to be communicated by both parties and be reflected in the final draft.

- When the final draft has been negotiated, a Decision Memo is submitted by the Director of the Originating Division to either the Associate Vice-President, ERG, or the President (depending on the type of agreement; see Tool 4), seeking their review and approval to sign the agreement. The memo should provide information on the partner, on the strategic value of the partnership to IFAD, on the benefits and possible reputational implications of the partnership, and on the implementation period of the partnership. The memo should be cleared by LEG, GPR, and any other divisions that have been involved in negotiations.

- If EB approval is required (as in the case of an MoU with a new partner), the originating division should:

i. Notify SEC (Governing bodies Office) and request the inclusion of the agreement as an Agenda Item at the next EB meeting, agreeing with SEC on a Due Date for documentation;

ii.Prepare a short paper to submit to the EB requesting approval to sign the agreement. This is typically a 1-2 page document with the draft agreement included as an attachment. This should be uploaded to Scriptoria and fully cleared by the SEC Due Date.

\section{Getting the signatures}

- Choose the right moment to seal the deal in collaboration with COM. For example, signing an agreement at a high-profile event leverages the event's publicity to give both your agreement and your organizations more visibility, maximizing the contribution to IFAD's Partnering Objectives.

- Signatures are done in person or by correspondence. In most cases, the President or the President's delegated authority - the GPR Director - signs for IFAD. If so requested in the decision memo and approved by the President, another person may sign, such as the Originator Division Director or Country Director. It is important to agree on who will sign for each party during the negotiations, and to specify this in the Decision memo requesting approval from the President.

- IFAD and the partner will agree on how the signing will be done: together in person or by mail. If an agreement is to be signed by mail, IFAD or the partner will sign first the two copies, and then send these to the partner for countersignature. One copy should be returned to IFAD. LEG provides a finalized copy of the agreement ready for signature. If the partner signs first and sends the document to IFAD for countersignature, it is essential to review the hard copy carefully before signing to ensure it is identical to the final agreed version.

\section{Where to go from here?}

The formalities of a partnership are only one part of the equation. TOOL 6, next, will help you to get the "soft" side of starting a partnership right. 


\section{Effective partnership management and communication}

AIM OF THE TOOL

To put the foundations into place

for effective partnership imple-

mentation and open communi-

cation.

\section{WHEN TO USE IT}

You have a partnership agreement

in place and you are ready to

begin working with the partner.

\section{How this tool can help you}

The steps in the Scoping, Selecting, and Setting Up phases can take time. It is understandable that partners will want to get on with things as fast as possible. However, taking a little extra time to ensure the foundations for a good partnership are in place will smooth implementation and, along with a well-developed partnership agreement, can help avoid problems.

This tool provides ideas and tips for getting organized for successful implementation: how to get off to a good start, how to develop workplans, and how to develop good relationships between IFAD and its partners. In other words, this tool helps you to invest in good management and communication practices that will lead to a sustained commitment to results in your partnership. The funding and administrative aspects of IFAD operations are time consuming, and staff are often under pressure. The key message of this tool is "don't short-cut putting in place the foundations for effective partnership management". Doing so is likely to cost you much more time later on. Before you start do verify if there is an existing partnership in another IFAD Division. You may obtain useful feedback from a colleague.

\section{Get well underway with a kick-off workshop}

A well-planned kick-off meeting involving those who will have a role in the implementation of the partnership will go a long way in making sure that your implementation phase is off to a great start. The table below gives you some pointers to consider. Many IFAD initiatives that involve partnerships will already have some form of workshop or meeting at the start, such as country project start up workshops. Use the table below to check that you are optimizing these events to get the partnership operating smoothly early on.

Who to invite?

What should be on the agenda?

Who chairs or facilitates?
Try to ensure that both senior representatives of the partners and those who will be implementing the partnership are present. This is an important opportunity to get everyone on the same page and demonstrate commitment.

The agenda for a kick-off meeting needs three main elements:

- Celebratory and promotional:

- acknowledging efforts so far

- signing the agreement, if appropriate

- informing others of partnership, including through social media

- Relationship-building:

- getting to know each other

- sharing expectations and hopes for partnership

- Doing business:

- clarifying action plans

- finalizing the communication strategy

- getting on with implementation

Prepare the workshop together and ensure the way it is conducted gives profile to all partners.

Think about a neutral location with good access to all partners. Set the venue up in a way that encourages interaction and avoids formal meeting setups. 


\section{Build personal relationships and create incentives for engagement}

You don't need to become the best of friends with your partners' staff, but investing in developing personal relationships will result in a better communication and a more committed partnership.

\section{Here are a few tips:}

- Don't take personal relationship in the partnership for granted: think consciously about what is needed to make them work.

- Build a sense of shared underlying values and commitment. If staff from each partner feel that "hearts are in the right place", it will be easier to approach and overcome any difficulties that may emerge.

- Think about what the partnership means for those directly involved. Organizations and partnerships succeed when there is a good overlap of the needs and interests of the individuals and that of the collective effort.

- Regularly ask people how they are feeling about the partnership, what they are enjoying, what is frustrating them, and what their ideas for the future are. People like to feel they are being heard and that their opinions are valued.

- Privately and publicly acknowledge the efforts of people working on the partnership.

- People are generally motivated by a sense of purpose, feeling that they are succeeding and sensing that they have autonomy. Work towards a partnership that delivers these for everyone involved.

The partnerships in which IFAD engages are often working toward larger "system changes". Such changes may be challenging or confronting for people. In such circumstances, you made may need to think about using specific processes and skilled facilitators to help open up people's hearts and minds to rethinking assumptions and established ways of operating. Remember that the work of partnerships, despite good intentions, may often lie outside people's immediate organizational responsibilities, job descriptions, and performance incentives, both within IFAD and within the partner organization. It is thus important to think about what will motivate people to make a priority of putting effort into the partnership.

\section{Clarify workplans and commitments}

Once a partnership gets going, there may still be a lack of clarity about what is expected of who and by when, even if there is a clear partnership agreement. This can result in false expectations, leading to early frustrations, rather than success. So invest that extra bit of time to ensure clarity of roles, responsibilities, and workplans in the early stages of the partnership.

\section{Consider the following:}

- Share documents. This sounds obvious, but much confusion and even mistrust can arise if partners are not literally on the same page.

- Review decision-making and governance. Ensure there is a clear decision-making authority within the partnership. Review the partnership agreement and make sure there is clarity between the strategic guidance (formalized oversight from a board or committee) and the operational leadership (secretariat, day-to-day decision-making, and responsibility for workplan delivery).

- Have an agreed action plan. Make sure it is clear what needs to done and that roles and responsibilities are understood. Early successes based on good planning are important to build confidence and maintain commitment.

- Align commitments. Makes sure there is full understanding on all sides about what the partners have signed up for, and what is expected of each other. Check that people feel comfortable with and capable of delivering on these commitments. It is important that everybody becomes clear about what others are committing themselves to. Don't forget to also name each partner and appreciate the value they bring to the whole partnership.

- Agree on decision-making and governance. An effective governance structure should include a clear decision-making authority within the partnership. Distinguish between strategic guidance (formalized oversight from a board or committee) and operational leadership (secretariat, dayto-day decision-making, and responsibility for workplan delivery). 
Use the six objectives from IFAD's Partnership Framework to clarify IFAD's specific interests, objectives, and principles for partnering. See TOOL 2 for help articulating and prioritizing these objectives for your partnership.
Explore underlying principles and values. A straightforward discussion about deliverables may unexpectedly reveal differences in principles and values between partners. This is no reason for concern: in fact, it should be expected. Be prepared to explain why this partnership is important to IFAD, and be prepared to listen to other partners' reasons for partnering-which could be very different.

\section{Establish a partnership communications and meeting schedule}

Communicate, communicate, communicate! This might seem obvious, but so often it doesn't happen until there is a problem.

Agree on communication needs: Make sure expectations are clear for everyone about who needs to communicate with who, through what medium, and how regularly.

Create a clear schedule of meetings: The frequency and nature of meetings will depend on the nature of the work. But consider at least quarterly meetings and a thorough review every six or twelve months. Make sure meetings are planned in in people's agendas.

Clarify the communication medium: How would partners like to be communicated with on different types of issues? Check what works for people-face to face, online, or written? Informally check in: Give your partners a regular call or email to see how things are going, provide feedback, and check if they need any support or guidance.

Be creative: Try to make partnership engagements fun and rewarding. Include social activities, make meetings interactive with input from everyone, do field trips together, and think about how to communicate progress in visually engaging ways.

\section{Establish an external communications plan}

Profiling the partnership and its work to external audiences will be important for many partnerships. But this can be a sensitive issue if partners don't feel they are being adequately recognized, or their own communication protocols are not being adhered to. Some aspects of external communication may have been covered in the partnering agreement, but they need to be clarified and put into action early on in the partnership.

Agree on branding: Decide how the partnership will be branded and how the logos and branding of the partners will be used.

Establish protocols: Make sure it is clear to everyone who has responsibility for external communication, and which partners need to be consulted before the public release of information.

Develop a communication plan: Early on, and again whenever appropriate, develop a plan for external communication that describes audiences, the purpose for the communication, responsibilities, the medium to be used (websites, social media, press releases, radio, etc.), and key messages to be communicated.

IFAD communications toolkit: While IFAD has long been at the forefront of efforts to help poor rural people build better lives, today we work in an increasingly complex, competitive and changing environment. In response, we are transforming the organization to do this work more effectively, efficiently and on a larger scale. Communications is key to that job and, therefore, a toolkit has been created to help us all get the job done. 
Tennyson (2011) distinguishes five areas in which partners can learn from their own partnering experience:

1. Organizational culture change (e.g., learning that other organizations do things differently to IFAD, and sometimes more effectively);

2. Human resource development (e.g., engaging employees in the partnership in practical ways);

3. Dynamic networks (e.g., demonstrating the value to IFAD of these new relationships and the diversity of their reach and influence);

4. Better communications (e.g., endorsing IFAD through good publicity for the partnership's achievements);

5. Opportunities for getting 'out of the box' (e.g., creating new 'experiential learning' opportunities-such as job swaps, secondments, internships, and partnering workshops).

\section{Develop necessary capacities}

It is critical that those implementing the partnership have the capabilities to do so. Don't take this for granted: a core IFAD objective is to develop the capacity of its partners.

Complete a capability scan: Early on in the partnership, work with partners to quickly assess the capacities and skills needed to deliver on different parts of the work programme. Explore where each partner has the skills to contribute and where new capabilities may need to be developed. See the Resources section below for further guidance.

Design capacity building activities: Develop a plan to fill any gaps revealed by the capability scan. Remember that bringing partners together to develop new knowledge and skills can be a good way of building relations and understanding, and providing incentives for staff to engage in the partnership.

Ensure a balance of soft and technical skills: To deliver results, those working on a partnership will need a good balance of technical skills and soft skills, such as communication, management, leadership, and partnering.

Consider training workshops on partnering: It may be worthwhile to bring the core people involved in the partnership together for training on partnering that covers many of the aspects presented in this Toolkit. This can be a good way of setting a common understanding and laying the foundations for the soft skills needed for a partnership to work, while at the same time building relationships and trust.

\section{Agree on how to learn from experience}

Being explicit about the need to reflect and learn together will make it easier for partners to put concerns about implementation on the table and for the partnership to constructively find solutions to emerging issues.

Establish a "learning culture": Across the partnership, establish a culture of sharing ideas and experiences, raising concerns, and accepting that problems and challenges will be inevitable. In particular, when one partner is in a funding relationship with the other (as IFAD will often be), be careful of creating situations where emerging difficulties are "hidden" until they blow up into a major problem.

Ensure a good monitoring system: Learning requires good information about what is being achieved and why there are successes for failures. Partners need to agree on how the partnership will be monitored and reviewed, and they need to put in place effective mechanisms to do so (TOOL 8). Conduct regular health checks: You should implement regular review processes to check how the partnership is progressing (see TOOL 9). In the early phases, and during more difficult times, these might need to be more regular, but a good review process should be conducted at least yearly. These should be facilitated in an open and engaging way that encourages learning.

\section{Where to go from here?}

This tool assumes that the negotiation and documentation of the partnership agreement has been concluded. If that is not the case, check out TOOL 4 Negotiating and documenting partnership agreements to see which items may need attention before beginning implementation. Despite your best efforts in planning, your partnership may not work as expected. Use TOOL 7 Tips for troubleshooting partnerships for assistance on how to get a struggling partnership back on track. 


\section{Tips for troubleshooting partnerships}

AIM OF THE TOOL

To provide assistance with

challenges commonly

encountered during partnering.

WHEN TO USE IT

During the Implementation phase,

when things do not go as planned.

\section{How this tool can help you}

This tool helps you deal with common problems and challenges that can arise in the day-to-day work of partnering at IFAD, and gives guidance based on real experience from IFAD staff. These challenges do not need to be the end of your partnership. There are things you can do that can bring the partnership back on track or minimize potentially negative outcomes. What the next seven situations have in common is that they are almost never part of a work plan-yet they still frequently happen, despite our best planning efforts.

While this tool offers troubleshooting advice for partnering, it is essential that you also try to prevent these situations from occurring. TOOLS 3, 4, 5, and 6 are designed to provide a solid basis for good partnering practice by IFAD and, if implemented well, will significantly decrease the risk of partnership problems and conflicts. TOOLS 8 and 9 can also help you to identify areas that need preventative attention.

However, if problems do emerge, you'll need to negotiate a way forward for the partnership. The final part of this Tool gives you insights on how to negotiate effectively with your partners.

\section{Seven common troubleshooting situations in partnerships}

The seven challenges and the ways of dealing with them outlined below have been identified from the experiences of IFAD staff managing partnerships. Being aware of these challenges right from the start will also help you to take steps to avoid them.

\section{What if partners are not delivering to expectation?}

The issue:

- Despite partners' enthusiasm during the Setting Up phase, energy seems to be waning.

- This is harmful for the partnership, as it endangers the delivery of expected results.

Tips for dealing with the issue:

- First of all: diagnose. Has this arisen because you misjudged the partners' commitment to the partnership in the Selecting and Scoping phase? Is it because of a lack of capacity to deliver? Did key staff change, leading to continuity issues? Or did something change in the external context, which made the partner reassess the value and priority of the partnership?

- Address a lack of commitment quickly.

- Start with small group of committed members who can demonstrate that they can achieve targets.

- It is possible that the objectives and initial work plan were not clear enough, were not commonly understood, or were not communicated effectively. If it hasn't been done yet, formalize commitment as soon as possible by:

- Redefining clear objectives and expected results.

- Defining the clear added value and the payback of the partnership.

- Working together in a participatory way.

- Gaining commitment on resources when an action plan is defined;

- Check that each organization has the ability to partner, and put mitigating training or coaching into place. 
What if no action plan has been developed to back up a higher level good intention to partner?

The issue:

- High-visibility partnerships, often launched with senior staff at global events, can have difficulties maintaining momentum locally.

- This is harmful for the partnership, as it endangers the delivery of expected results. The reputations of those agreeing to partner may be at risks as ambitions are not realised

\section{Tips for dealing with the issue:}

- Check whether communication between the initiators of the global partnership and the countries or regions within IFAD has been adequate.

- Make an effort to translate the overall partnership goals into the local context: what's in it for them?

- Listen to feedback from local perspectives on why things are not moving. A lack of reporting does not mean there is no useful feedback or lessons learned.

- Be open to the possibility that a global partnership idea has not been sufficiently tested and validated locally. Creating local ownership is the priority. Ask: 'Under which conditions would this partnership deliver value for you?"

\section{What if essential staff leave the organization?}

\section{The issue:}

- Staff turnover is a fact of life for everybody.

- If it occurs on a large scale, or at a critical moment in the partnership, it creates risks for the partnership that need to be addressed.

\section{Tips for dealing with the issue:}

- Diagnose whether the departure of key staff is a coincidence, or a signal that there are underlying issues to be addressed with the partner or within the partnership.

- Create a habit of documenting effectively: don't just include the bare essentials, but also take note of informal matters, such as access to the networks of a particular partner.

- Promote collaborative leadership for the partnership. This enables responsibilities to be shared between multiple people, reducing the risk of collapse if an essential person leaves; it also increases ownership and brings more leadership resources and styles into the partnership.

\section{What if externalities disrupt the work plan of the partnership?}

The issue:

- No matter how well your partnership plans are negotiated and written out, disruptive events can happen.

- Whether these disasters are natural or man-made, they can cause disruption to your partnership.

\section{Tips for dealing with the issue:}

- Take stock with your partners of whether this externality is a reason to put the partnership on hold, or whether workarounds are possible.

- Adapt work plans and expectations in order to avoid confusion and to provide clarity to partners, who already face increased stress due to the events.

- Discuss whether the external events are a reason to shift the focus of the partnership to respond to the immediate needs of rural people. This could be common sense, but may also be the preferred ethical choice. 


\section{What if poor staff performance needs to be tackled?}

The issue:

- If partners underdeliver because of poor staff performance, it puts the results of the partnership at risk.

- IFAD needs to respect the autonomy and mandate of the partner, so it cannot directly interfere in internal staffing matters.

\section{Tips for dealing with the issue:}

- Check whether the perceived poor performance is due to inability or unwillingness. Unwillingness may be personal ("I don't like my job”), or more systemic ("My boss or organization tells me not to give priority to this partnership").

- Depending on the cultural context, there are always diplomatic options for informing the partner of poor performance. Avoid direct confrontation.

- Discuss poor performance with the supervisor in a delicate manner. For example: "Your guy is very good, but he is very busy. Can you send someone to help him give attention to this project?"

- Try to avoid complaint and gossip within the partnership. This creates negative attitudes of blame-shifting and responsibility-avoidance.

\section{What if you suspect serious violations of the Code of Conduct?}

The issue:

- You suspect that one of the partners is corrupt, or otherwise in serious breach of IFAD's Code of Conduct.

- IFAD needs to safeguard its operations from the risks associated with such violations.

Tips for dealing with the issue:

- Don't try to tackle these issues alone. Inform your supervisor and draw up a plan of action.

- Stay close to IFAD's established procedures. Start here.

\section{What if there are issues with partner recognition?}

The issue:

- All partners are sensitive about being seen and recognized for their contributions to the partnership.

- Logos and visibility in reports and events are a key source of conflict in partnerships.

- Partner recognition could also concern partners not feeling involved in the decision-making.

Tips for dealing with the issue:

- Make clear agreements beforehand by including a communications strategy in each partnership agreement (see TOOL 4, Negotiating and Documenting a Partnership Agreement) and use TOOL 6, Effective Partnership Management and Communication.

- Early on, discuss with partners which items to communicate as a partnership, and which language should be used.

- Establish clear decision-making rules: what does IFAD decide? What do we decide as a partnership? What do we decide by ourselves? 


\section{How to negotiate a way forward}

In any of these situations above, you'll need to negotiate a way forward for the partnership. A classic work in the field of negotiation is Getting to Yes: Negotiating Agreement without Giving In by Roger Fisher, William L. Ury, and Bruce Patton. Here is a brief summary of what these authors call "principled negotiation": a way to reach agreement without jeopardizing business relations.

\section{Separate the people from the problem}

- Most conflicts are based in differing interpretations of the facts. It is crucial for both sides to understand the other's viewpoint.

- The parties must acknowledge that certain emotions are present, even when they don't see those feelings as reasonable.

- The listeners should give the speaker their full attention, occasionally summarizing the speaker's points to confirm their understanding. Speakers should direct their speech toward the other parties and remain focused on what they are trying to communicate.

\section{Focus on interests rather than positions}

- Defining a problem in terms of positions means that at least one party will "lose" the dispute. When a problem is defined in terms of the parties' underlying interests, it is often possible to find a solution that satisfies both parties' interests.

\section{Generate a variety of options before settling on an agreement}

- Separate the invention process from the evaluation stage. Only after a variety of proposals have been made should the group turn to evaluating the ideas. Evaluation should begin with the most promising proposals.

- Avoid falling into a win-lose mentality; focus instead on shared interests.

- When parties' interests differ, seek options in which those differences can be made compatible, or even complementary. The key to reconciling different interests is to look for items that are of low cost to you and high benefit to them, and vice versa.

\section{Insist that the agreement be based on objective criteria}

- Decisions based on reasonable standards makes it easier for the parties to agree and preserve their good relationship.

- Criteria should be both legitimate and practical. Scientific findings, professional standards, and legal precedent are possible sources of objective criteria.

\section{Establish your best alternative to a negotiated agreement (your "BATNA")} before entering into a negotiation. The reason you negotiate is to produce something better than the results you can obtain without negotiating. Agreements that would leave you worse off than that should be rejected.

\section{Where to go from here?}

It is not always evident why a partnership is not working well. To improve the quality of the partnership and to establish a regular overview of its functioning, use TOOL 9, the Partnership Health Check. 


\section{Monitoring and reporting on partnerships}

AIM OF THE TOOL

To provide guidance on to how

to monitor partnerships so as to

improve their performance and to

meet IFAD reporting requirements.

WHEN TO USE IT

Use this tool when you start put-

ting a monitoring system in place

for your partnership, and when

you need to report. However,

monitoring issues should be kept

in mind right from the very begin-

ning of your partnering process.

\section{How this tool can help you}

This tool provides guidance on what to monitor in a partnership, how to set up monitoring with your partner, how to use monitoring to improve the partnership, and how to report on your partnership within IFAD systems. This tool links to TOOL 9 , the partnership health check.

\begin{abstract}
Effective monitoring and learning within your partnership are a critical parts of putting good partnering principles into practice. A good monitoring and review process developed with your partner will enable you to be more strategic and responsive, work in collaborative, transparent, and accountable ways, and improve the culture of effective partnering. Investing in a simple, clear, and effective monitoring system will help your partnership to be more effective and results-oriented.
\end{abstract}

IFAD has committed to more comprehensive reporting on how partnering is enabling it to deliver on its mission and results. To do this effectively requires input from those responsible for partnerships, be it on the project, country, regional, or global level. This tool outlines the expectations for such reporting, and describes how it should be done within the framework of IFAD's results management and information systems.

\section{What are the key elements of partnership monitoring and reporting processes?}

The monitoring, evaluating, and reporting of partnerships is in essence no different to the monitoring, evaluation, and learning (MEL) of any project or programme. The same principles and approaches apply. The monitoring and reporting of your partnership may be integrated into a MEL of a wider project or programme. This tool does not cover general MEL practices, so if you are new to monitoring, evaluation, and learning, it may help to have input from a MEL specialist.

The monitoring and reporting of your partnership will need to be developed around the following five key elements:

1) Identify monitoring and review questions, indicators, and criteria: The starting point is for the members of the partnership to agree on what needs to be monitored to assess the performance of the partnership and to verify that it is delivering on expectations and on the intended results. This will generally involve collecting sets of both qualitative and quantitative information (see the next section for details on what to monitor)

2) Development and implement monitoring mechanisms: Once you know what information you need, work out how it is going to be collected, collated, analysed, and shared, and determine who is responsible for this. Common sense? Yes! But if the practical mechanisms are not in place you will not get the information you need.

3) Use monitoring information to review partnership performance and conduct health checks: The primary purpose of monitoring the partnership is to verify how it is going, to learn from experience, and to identify how improvements could be made. This requires regular engagement discussions between the partners, so make sure time is set aside for this to be done. About once a year, conduct a structured partnership "health check" - Tool 9 explains how.

4) Use the outcomes of monitoring and review to improve the partnership: Make sure you go full circle. Use the information generated from monitoring and the insights generated from review processes to take decision within the partnership so as to improve how it is working and the results it is delivering.

5) Feed information about the partnership into IFAD's partnership reporting system: There are mechanisms for country, regional, and global reporting on partnerships. Contributing information from your partnerships to this system will enable IFAD to meet its responsibilities for corporate-level reporting on partnerships. 
6) Use monitoring and results to promote and celebrate the partnership: Don't forget to use the achievements of your partnership to promote its value and the work of IFAD and its partner. Also, find ways to celebrate what has been achieved with your partner, and to acknowledge those who have contributed.

\section{Overview of partnership monitoring and reporting mechanisms}

The 2019 IFAD Partnership Framework identified ways of strengthening the monitoring and reporting on IFAD partnerships. As far as possible, improved partnership monitoring and reporting is integrated into existing IFAD procedures and mechanisms; see Figure 8.1.

As outlined in Section 5 of this tool, partnerships are monitored and reported on in different ways at country (COSOP), project, regional, and global levels, as well as within grants. The overall monitoring and reporting on partnerships within IFAD involves a combination of reporting through the Results Management Framework (RMF)/ORMS, annual summary notes produced on the county, regional and global levels, rating scales within project and COSOP reviews, OIE evaluations, the client survey, and partnership surveys. This information will be synthesized into a Corporate Partnership Report each replenishment period.

It is important that you understand the partnership monitoring and reporting requirements and the mechanisms for the IFAD business processes that connect to your partnership. You can seek more detailed guidance on this from GPR.

To enable better reporting on partnership results, the identification of partners and partnering objectives have been strengthened across IFAD's business processes. This includes development of regional engagement and partnering strategies, and an enhanced global level partnership strategy in COSOPs. These mechanisms enable greater clarity on how partnering contributes to achieving IFAD's mission and provides a basis for better assessment of the degree to which partnerships are meeting expectations.

M\&E

Requirements

M\&E

Mechanisms

\section{Partnering Indicators}

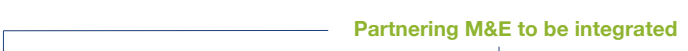

$\downarrow \quad$ Partnering M\&E

Information Systems

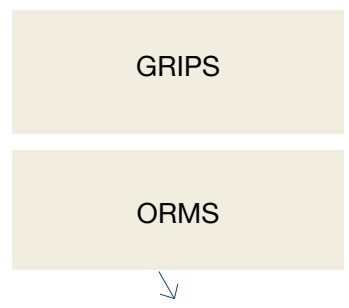

ME Processes

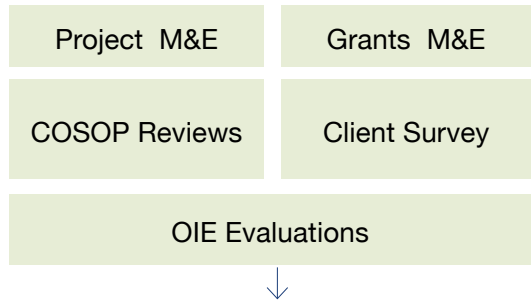

Additional Processes

Summary Notes on Country, Regional and Global Partnerships (Annual Highlights and Lessons)

Regional and Global Partnership Survey

Case Studies for Partnership Report
Overall

Reporting

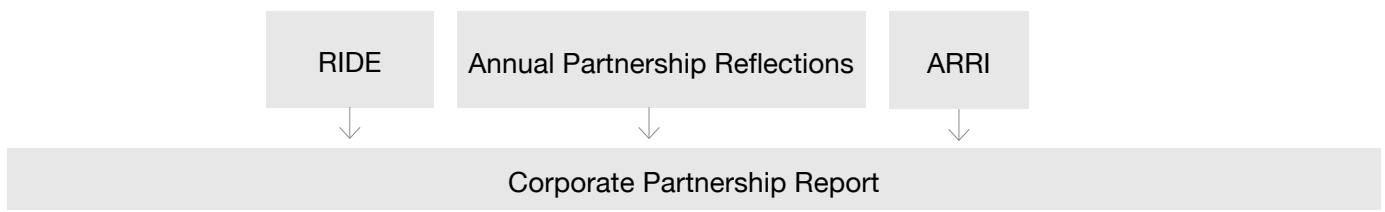

For acronyms see list on page 3 


\section{What needs monitoring?}

You will need consider monitoring questions and indicators for three aspects of a partnership:

1) The specific results and impacts intended by the partnership;

2) How well the partnership is functioning - the process of the partnership;

3) The contribution of the partnership to IFAD's partnering outcomes and objectives (see TOOL 1)

Box 8.1: Partnering performance criteria

1. Purpose: Are our partnering goals, values, and objectives clearly articulated, agreed, and still relevant?

2. Results: Are we delivering on our expected partnership results and impacts?

3. Value: Are we as an organization getting value from our involvement in the partnership?

4. Governance: Have the roles, responsibilities, and work processes been clearly agreed upon and documented, and are they being followed?

5. Leadership: Is the partnership being led in an effective, responsive, and flexible way?

6. Engagement: Is there sufficient commitment, engagement, and trust from the partner organisations?

7. Resources: Are there sufficient financial and human resources and facilities for the partnership to deliver on expectations?

8. Equity: Is the partnership equitable, transparent, and accountable for all partners?

9. Process: Are communication, planning, team development, and meeting and monitoring processes adequate and effective?
Monitoring the results and impacts of a partnership should follow standard M\&E practices. Most partnerships will be linked to the delivery of a project or programme that will have identified the intended outputs, outcomes, and impacts. The degree to which these are achieved and the contribution the partnership has made is the basis for monitoring the results and the impact of the partnership. As with all M\&E, the initial challenge is to ensure that the intended results have been sufficiently well defined for them to be effectively monitored.

Monitoring how the partnership is functioning will help with the early identification and resolution of any problems that could prevent the partnership from delivering on the expected results and impacts.

Box 8.1 provides a list of criteria for assessing the overall performance of a partnership, and forms the basis of the partnership health check detailed in TOOL 9. These criteria are drawn from the partnering principles and partnering checklist in TOOL 1.

The IFAD Partnership Framework identifies a set of high-level outcomes and objectives to which all IFAD partnerships should contribute in some way. The table below provides an overview of what needs to be monitored to show this contribution. 
Table 8.1 Assessing IFAD's partnering outcomes and objectives

Outcomes/objectives

Country impact at scale

Partnering

outcomes

$\begin{array}{ll} & \\ \text { Influence on enabling } \\ \text { environment }\end{array}$

Capable and effective partners

\section{What to monitor}

The increased reach and impact that IFAD can have on rural poverty through partnerships that leverage financial resources and extend country implementation capacity

The ways that IFAD partnerships have led to a more supportive national, regional, or global contexts for tackling rural poverty, such as policies, investments, rural services, and inclusive business

How the local, national, or international organizations that support rural people and rural development, and who partner with IFAD, have become more capable, effective, and sustainable as a result of the partnership.

The ways that partnerships enable IFAD to have greater effect in bringing about policy changes and development agendas that are more supportive of rural poverty alleviation at the national, regional, or global level.

The extent to which partnerships increase the scale of resources being used to implement rural development projects and programmes

The ways in which IFAD is working with national level platforms, coalitions, and other partnerships to support a country-led approach to rural development backed by effective coordination between development organizations

Brokering knowledge and Innovation

The ways partnerships with knowledge institutions -including the CGIAR, universities, and national agricultural research centres - are enabling IFAD to achieve greater reach and impact through new technologies, management practices, communication approaches, and evidence-based policies.

How engagement with the private sector is helping to create inclusive agriculture and food systems through better market access, improved service provision, and financial contributions to rural development initiatives.

Enhancing visibility
The ways in which partnerships -including participation in multistakeholder platforms - enable IFAD to achieve greater visibility at the national, regional, or global scale for the work it does and the issues it promotes. 


\section{Monitoring mechanisms across IFAD business processes}

Table 8.2 below provides an overview of the partnership monitoring and reporting mechanisms within the different IFAD business processes.

Table 8.2 Monitoring and reporting mechanisms

\section{Business}

process

Cosop

Country project and programmes

Grants

\section{Regional} engagement

\section{Global} Engagement

\section{Overview}

Directions for country partnership development are specified in the COSOP, according to the COSOP guidelines appendix. This provides a basis for monitoring.

Partnership monitoring at the project level is integrated into the result framework and ORMS (in webapps, also check the supporting material).

The monitoring and reporting on partnership aspects of grants are integrated into the grant proposal, supervision, and completion processes

Regions complete a light regional engagement and partnership strategy which provides the basis for monitoring and reporting. A brief annual summary of progress report is prepared.

GPR prepares a rolling global engagement strategy linked to the replenishment period and an annual workplan. These provide the basis for monitoring.
Monitoring and reporting mechanisms

- Brief annual report on partnerships provided to GPR

- Scoring in CRR and CCR

- Client survey

- IFAD results management framework

- ORMS

- Scoring and comments in MTR and PCR

- ORMS grants module

- Grant reporting and completion

- Regional engagement and partnership strategy

- Annual summary of progress report provided to GPR

- Regional and global partnership survey

- Global engagement strategy

- Annual global engagement workplan

- Annual partnership progress report

- Partnership survey

- Replenishment period partnering report

\section{Partnership monitoring and reporting checklist}

Use the table below to provide a quick traffic-light check on the monitoring and reporting of your partnership, in order to identify areas where improvements could be made.

Have the intended objectives and outcomes of partnership been clearly established in a way that can be monitored?

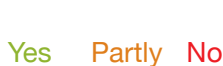

Have the partners discussed and agreed on how they will assess the performance and success of the partnership?

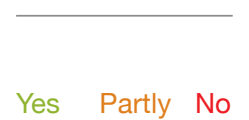

Have relevant qualitative and quantitative indicators been developed to monitor the partnership and its outcomes?

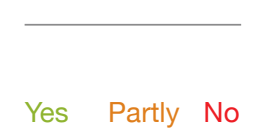

Have the necessary
monitoring
and reporting
mechanisms been
put in place?

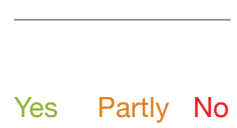

Is monitoring and evaluation being used to improve the quality and impact of the partnership and to promote its benefits?

Are partnership outcomes being reported to enable IFAD-wide corporate reporting on partnerships?

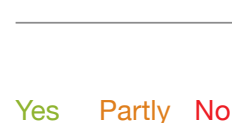

. 


\section{Partnership health check}

AIM OF THE TOOL

To improve the quality of the partnership and to establish a regular overview of the functioning of the partnership.

WHEN TO USE IT

During the Monitoring and Review phase when you are revisiting an existing partnership, whether at project, COSOP, grant, regional, or global level. It is additional to the regular IFAD review processes.

\section{How this tool can help you}

This tool can help you review your partnership on a regular basis. It provides a set of criteria for checking partnership health and a process for conducting a health check with your partners. The tool includes a template based on the health check criteria. There are different ways to use this tool. You can use it to quickly assess which areas of your partnership are in good shape and which need more attention. It also provides guidance on how to conduct an in-depth and interactive review session with your partners.

It is good practice for partners to regularly review the partnership. This establishes common ground on what is working well and what isn't. A partnership health check provides an opportunity for open discussion about all aspects of the partnership-alongside the usual focus on the partnerships' activities and results. This helps you prioritize the actions to be taken in the next period, and to adjust strategy or plans where needed. This health check is different to IFAD review processes for projects, COSOPs, and grants, but may sit alongside and complement them.

Make sure that the Partnership Agreement documents are known to everyone involved (see TOOL 4). Use information from the M\&E system on the progress and results of the partnership (see TOOL 8 to support the health check process). Having regular health checks with your partners is sensible: it decreases risks (by spotting strategic and implementation issues in time) and increases effectiveness (by enabling an honest conversation about things that could be improved, or that need to be taken into account by the partnership).

\section{Criteria for assessing the health of a partnership}

The nine key criteria and associated questions for checking the health of a partnership, below, draw on the partnering principles and the partnering checklist in TOOL 1 . They cover whether the partnership is delivering on expectations, as well as the mechanisms, processes, and relationships needed for an effective partnership.

These criteria can be adapted in number and nature to meet the specific needs of a particular partnership. It is a good idea to discuss these criteria during the Setting Up phase of your partnership, and to agree on how the performance of the partnership will be assessed.

1. Purpose: Are our partnering goals, values, and objectives clearly articulated, agreed on, and still relevant?

2. Results: Are we delivering on our expected partnership results and impacts?

3. Value: Are we receiving value as an organization from our involvement in the partnership?

4. Governance: Are roles, responsibilities, and work processes clearly agreed on and documented, and are they being followed?

5. Leadership: Is the partnership being led in an effective, responsive, and flexible way?

6. Engagement: Is there sufficient commitment, engagement and trust from the partner organizations?

7. Resources: Are there sufficient financial and human resources and facilities for the partnership to deliver on expectations?

8. Equity: Is the partnership equitable, transparent, and accountable for all partners?

9. Process: Are communication, planning, team development, meeting, and monitoring processes adequate and effective?

These criteria can be plotted on a spider diagram using the template provided at the end of this tool. You can plot the different views of individual partners to determine where there are differences in opinion or perception. This can help you to discuss the most important points. 
Figure 9.1: Example of Partnership Health Check filled out by two partners, showing their perception of the partnership as a whole. Differences in perception are items for partnership learning.

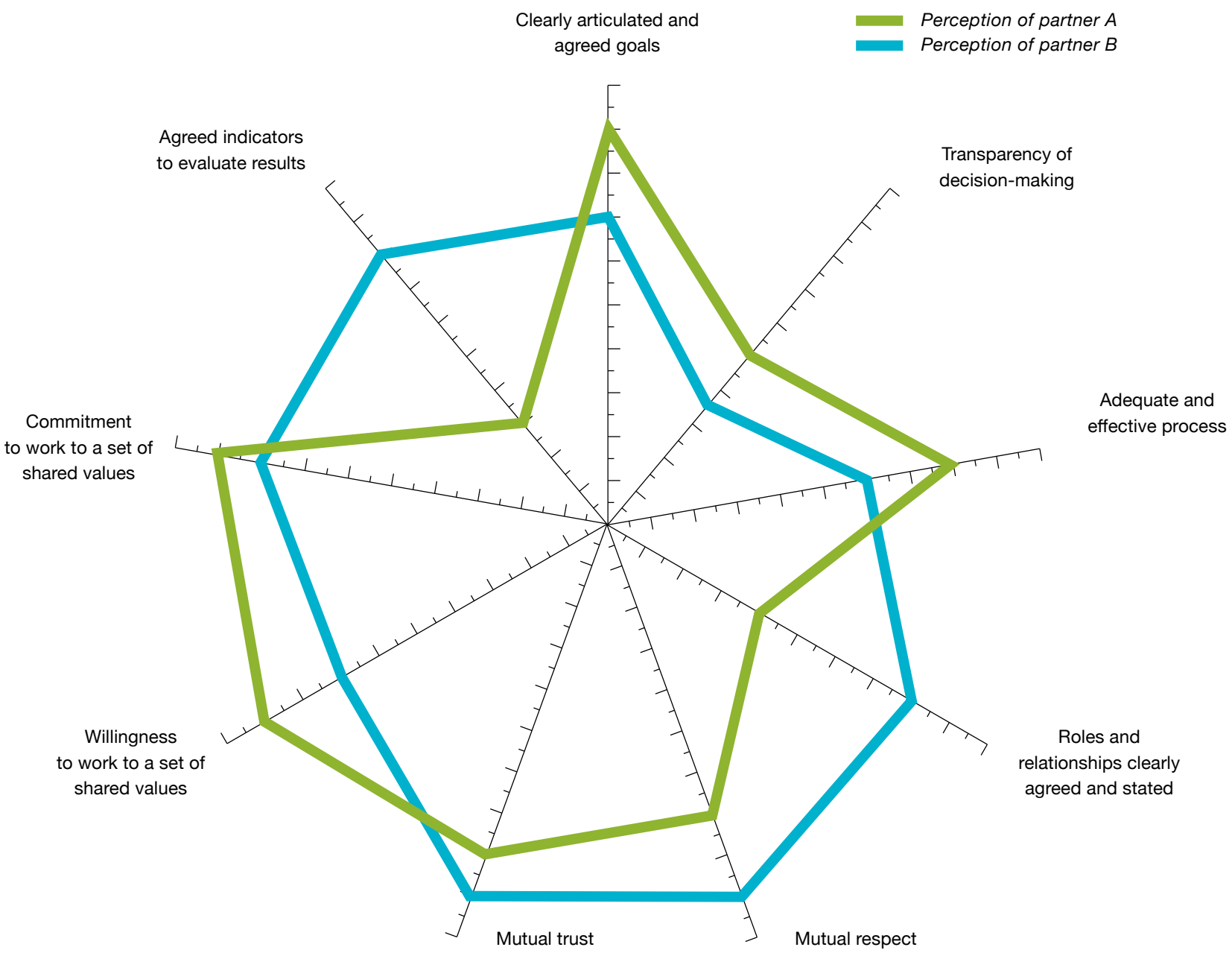

\section{Conducting a health check}

A health check can range from a one-hour session as part of a regular planned meeting with partners to a more substantial annual review exercise that could take up to a full day. What is needed will depend on the scope of work, the complexity of the partnership, and the extent of any emerging issues.

It is suggested that all partnerships conduct some form of health check as a joint partnership exercise on at least an annual basis. Use the health check criteria and template as a basis for the health check process.

\section{An indicative process for a health check is as a follows:}

1) Agree with partners on dates, length, and who will participate.

2) Agree on the criteria that will be used to conduct the health check.

3) Start the health check meeting with engagement and "warm up" activities that get people comfortable and talking with each other.

4) Ask people to reflect on what have been the successes and highlights of the partnership for them, and where they see challenges.

5) Use the health check template below to elicit individual reflections on how people see the partnership, according to the health check criteria.

6) Examine higher and lower ratings, differences in perceptions, and the reasons for these.

7) Agree on any actions that need to be taken to improve the partnership.

\section{TIP}

A convenient way to structure the discussion of the diagram is to ask the following questions:

What? What do you see happening in the partnership? Why? What explains what we can see?

So what? What are the implications of these insights? Now what? What actions do we need to take? 


\section{Using the health check template}

The process of applying this health check template with your partners has two main steps:

1. Review the criteria for checking the partnership's health:

a. Clarify the purpose of the exercise: it is not an evaluation, but to enable a conversation about improving your partnership.

b. Discuss the nine criteria for assessing the partnership, so that the group comes to a common understanding.

2. Examine the partnership using the agreed-on criteria:

a. Give each person an A4 print of the empty diagram (worksheet 9.1).

b. Decide on the extent to which the partnership currently meets each of the nine criteria. Individuals should complete their own copy using the following key:

\section{Key}

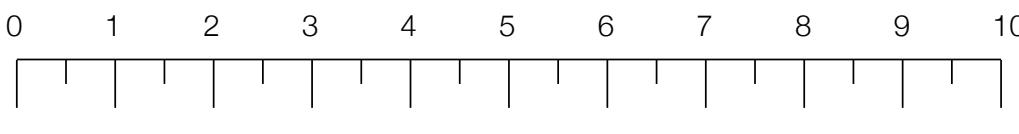

very low low high very high

c. Each person is then asked to plot their assessment on a large flipchart by marking their scores on each axis and joining the dots. Prepare this flipchart beforehand with a large empty spider web with nine axes. Each person should use a differently coloured pen, if possible.

$\mathrm{d}$. The diagram can then be used as a basis for discussion about the partnership: making comparisons, exploring the differences in scores and what these differences represent; identifying issues or problem areas that need to be addressed; and generating ideas to strengthen the partnership.

\section{TIP}

You can use this instrument by yourself if there is no opportunity to perform it with your partners, or if you wish to reflect on the partnership as part of your monitoring and reporting requirements.

\section{TIP}

If you feel that a criterion is missing or is redundant for your particular situation, you can decide to add or change it. Make sure that everybody agrees and understands why this is happening.

\section{TIP}

If you need to do this activity online instead of face-to-face, you can paste a screenshot of worksheet 9.1 to an online whiteboard such as Mural or Miro. Ask participants to score by placing post-its or dots on each axis. Make sure you include the agreed-upon criteria. 
Worksheet 9.1: Partnership health check

Criterion 9

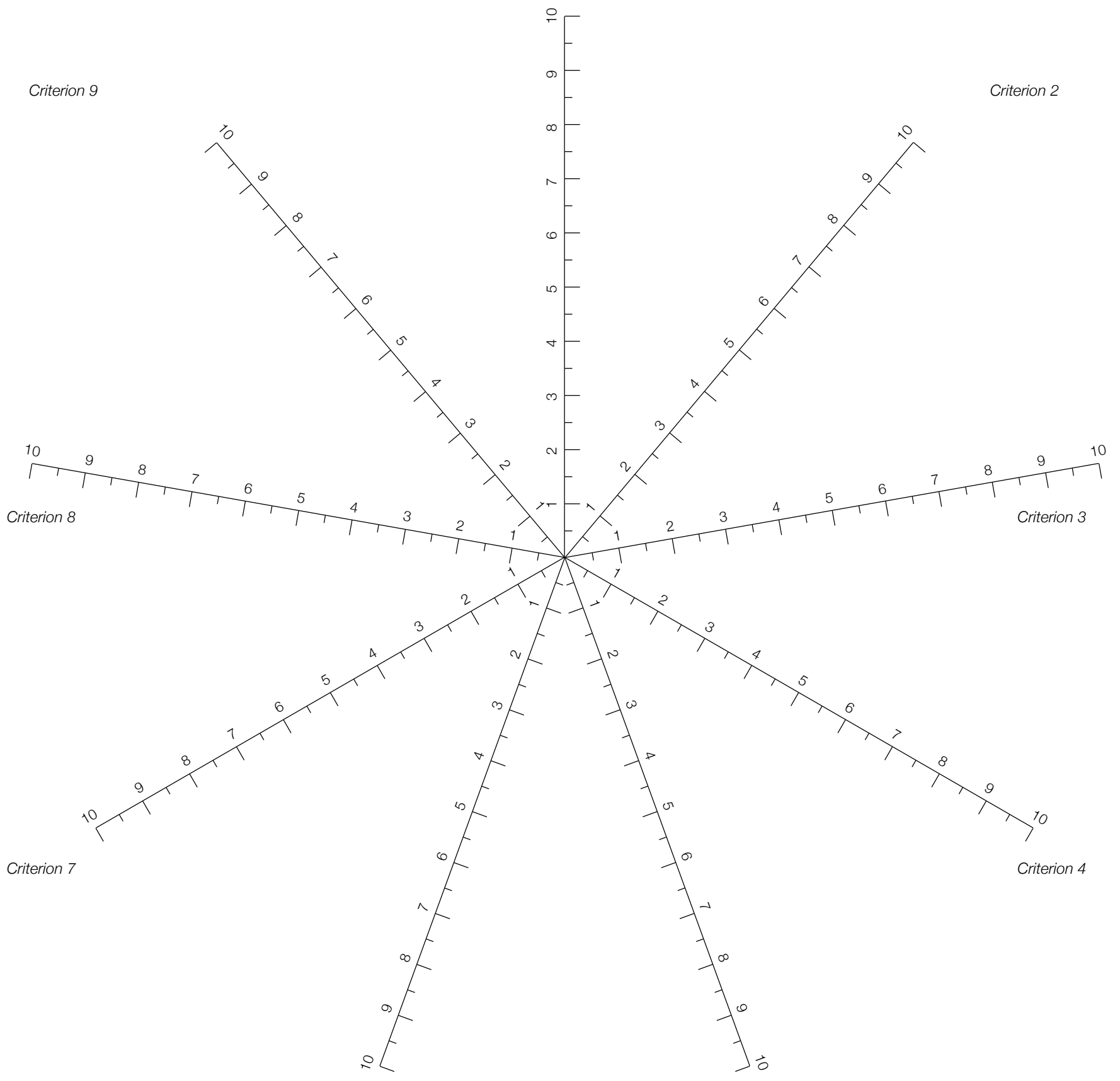

\section{$\stackrel{\circ}{-5}$}

Criterion 2

Criterion 6

Criterion 5

Key

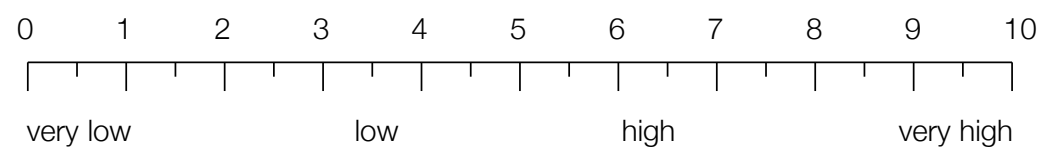

Where to go from here?

Use TOOL 7 Tips for troubleshooting partnerships, for assistance on how to deal with some of the challenges identified in this partnership health check. For specific guidance on partnering with governments, partnering with the private sector, and working with complex multistakeholder partnerships, refer to TOOLS 10, 11, and 12 respectively. 


\section{Partnering with government}

AIM OF THE TOOL

To improve the quality of partner-

ing with governments, recogniz-

ing the differences in contexts

between fragile, low income, and

middle-income countries.

WHEN TO USE IT

During the Setting Up or

Implementation phase, when you

are experiencing challenges in

your government partnership-

whether in relation to a project,

COSOP, or grant.

\section{How this tool can help you}

Governments are the core partner for IFAD country programmes. Because of their central role, aspects of partnering with them cannot be taken for granted. There are key elements of partnerships with government that require constant attention and review, careful negotiation, and high levels of political and cultural sensitivity. This tool outlines key factors to consider in ensuring an effective partnership between IFAD and the host government, and gives ideas about how to tackle challenging situations.

It also provides an overview of the special factors to consider when of partnering with governments in fragile contexts or in upper middle income countries (UMICs).

\section{What is specific about partnering with government?}

Unlike partnering with other development actors - where IFAD may have a choice of partnersthe government is the foundation of each IFAD country programme. Despite the challenges and difficulties, you have to make the partnership work. There are big differences in the capacities and political and cultural contexts across the countries where IFAD works. Further, country partnerships are also often highly influenced by the personalities and interests of political leaders and senior government officials. A good understanding of, and sensitivity to, the political and cultural context is a critical starting point.

In partnering with governments, IFAD staff make two important observations:

1) While the partnership with IFAD is generally seen positively by government, IFAD staff may experience the partnership as more challenging, due to their responsibilities for ensuring the agreed results are being achieved on time and within budget.

2) The partnership between IFAD and government is fundamental to many other partnerships that are taking place in a country. If the quality of partnering with governments is poor, it puts other partnerships at risk.

This means that it is critical to optimize the quality of partnerships between government and IFAD. Alongside the official loan agreement, there are many "softer" informal aspects of guiding and managing the partnership to consider. There will always be ways to improve the partnership. Three common challenges are recognized by IFAD staff in partnering with government: capacity challenges, accountability challenges, and continuity challenges. Worksheet 10.1 offers examples of these and some ways to deal with them suggested by PPPlab. 
Worksheet 10.1: Mitigating challenges of partnering with government

\section{Challenge 1: Capacity}

\section{For example due to:}

- unreliable government funding

- limited human managerial resources

- limited technical resources

- lack of partnering and collaboration skills

\section{Ways to mitigate:}

- budget sufficiently for TA function in projects

- locate the project management unit (PMU) within government so as to optimize knowledge transfer to government

- develop national capacities (especially in the more remote devolved government structures), while directly enhancing project effectiveness through hands-on, professional nurturing

- create communities of practice where IFAD staff and other development partners can exchange good practices on partnering with government

How does this challenge present itself in your situation? What could you do about it?

\section{Challenge 2: Accountability}

\section{For example:}

- there is insufficient commitment and management oversight

- government departments do not deliver on agreements and commitments

- officials operate in ineffective or corrupt ways

- partnership resources are not used as agreed

\section{Ways to mitigate:}

- develop the financial capacity of national stakeholders through training and handson mentoring

- increase the quality of the assurance function (external audit)

- use steering committees or other governance structures to insist on adherence to the partnership agreement and loan agreement

- seek collaboration with other UN agencies and IFIs to pool expertise on project monitoring and control

- if incentives to deliver are missing for government, identify where a change in incentives might shift action on the ground

\section{How does this challenge present itself in your situation? What could you do about it?}

\section{Challenge 3: Continuity}

\section{For example:}

- elections and political change alter policies or lead to a replacement of counterparts,

- external factors, natural disasters, financial conditions, and conflicts alter the operating conditions

- regulatory constraints limit government's flexibility and create delays

\section{Ways to mitigate:}

- ensure the project involves government staff from different levels

- put contingency capacity building measures in place (like training several staff members for the same function)

- build multistakeholder platforms of government departments, civil society, private sector, and knowledge institutes to ensure broad ownership of IFADsupported projects

- use early warning systems to 'be in the know' when-or before-things go wrong

How does this challenge present itself in your situation? What could you do about it?

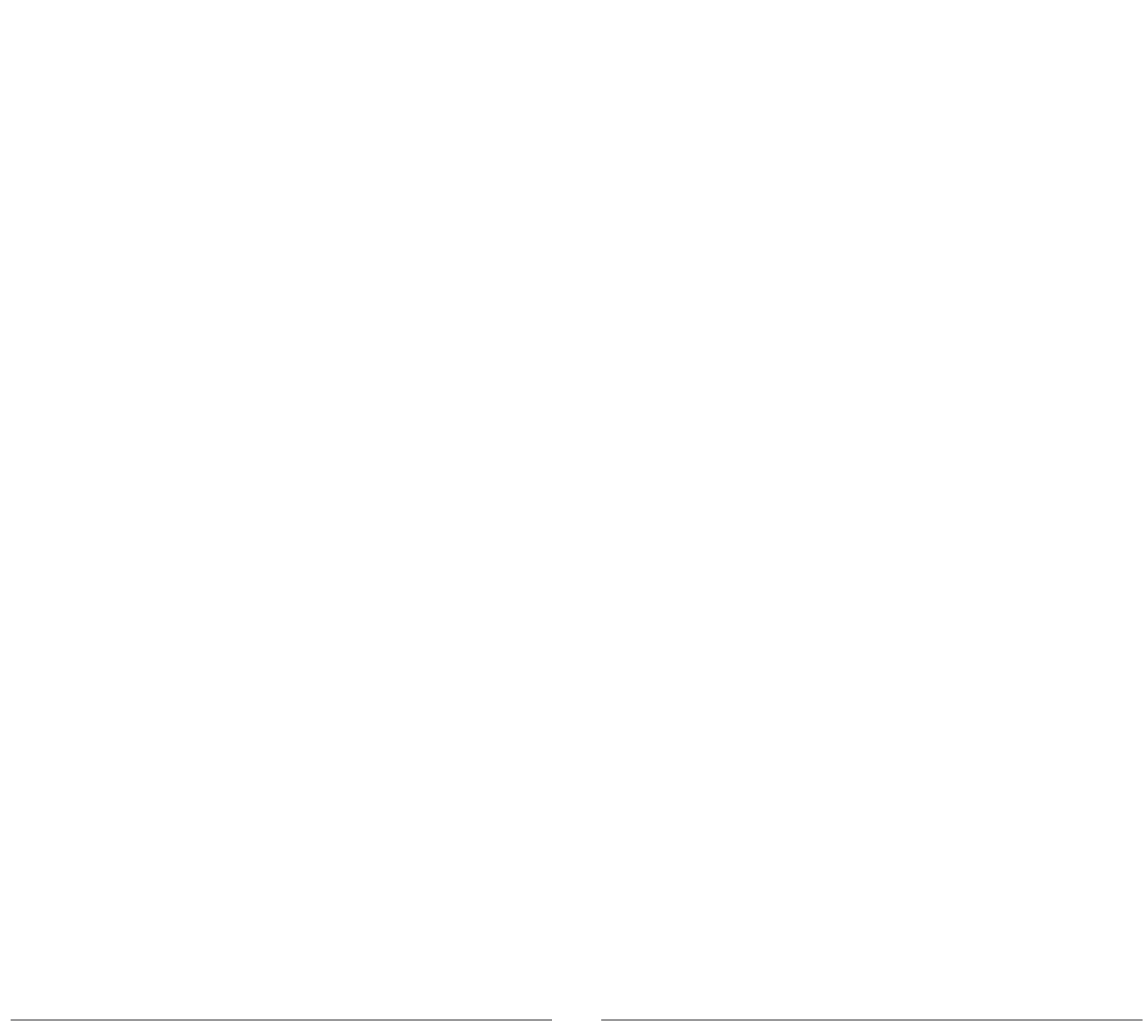




\section{Understand the context and interests}

Guiding a partnership between government and IFAD can be a tricky and politically sensitive task, requiring a significant level of diplomacy. You will often be dealing with multiple levels of government, and with influential personalities from across the spheres of politics and the civil service. There are likely to be numerous different institutional and person interests at play, some complementary and some competing, some explicit and some implicit. There is no blueprint to managing these dynamics, and much of it will come down to experience and the quality of personal relationships.

You will be much better prepared to work with these dynamics if you have a thorough understanding of the political economic context of the country and of the personal and institutional interests of the main government players. Develop as much of an understanding as you can of the political economic context by reading widely and talking to as many informed people as possible. Try to understand the formal and informal power dynamics, and how this might influence the partnership. To help in the process, you may find it helpful to consider the following mapping exercise of roles, responsibilities, and interests. This tool can be used more generically, but is specifically used here to clarify roles of government players in partnerships.

Worksheet 10.2: Mapping the roles, responsibilities, and interest of government players

\section{Players}

Who are the key government players that are critical to the partnership?

\section{Interests}

What are their main institutional and personal interests, explicit or implicit?

\section{Role}

What is their role?

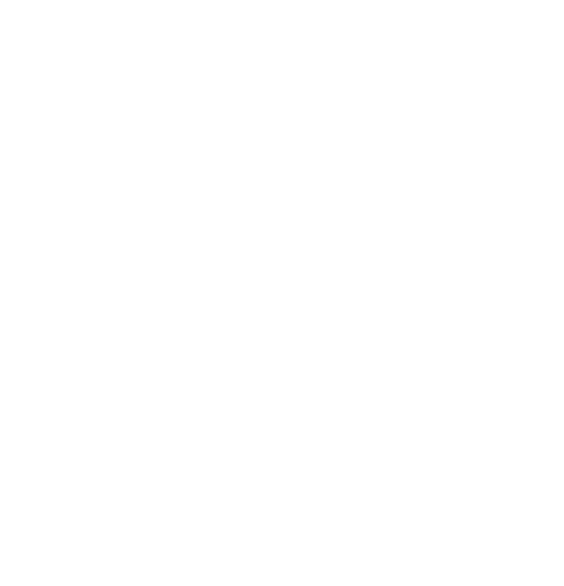

Alignment of interests

Where do these interest align or conflict with the interests of other players?
Responsibilities

What responsibilities do they have in relation to partnership?

Implications

What are the potential implications for guiding the partnership? 


\title{
Tips to help strengthen government partnership
}

\author{
Here are eight tips for CDs provided by seasoned IFAD colleagues:
}

1) Always verify and monitor country ownership. Here are some indicators that can help to see whether the government is truly in the driving seat:

a. Is the government contribution being delivered?

b. Is the Steering Committee actually meeting?

c. Is the project being mentioned by government officials in documents, at conferences, and in the press?

2) The key to success in partnering with government is understanding government partners' interests and benefits, and acting on this. Combining interests is the first partnership principle to take into account.

3) Continuously review the ways of working with the governmental partner. You can use Tool 5 on developing a partnership agreement to do so.

4) Understand the level of formality and hierarchy in a country. In some countries you can tap into the President, while in others you may not even be able to meet a Minister. Make a plan and have clear protocols for how to work given the context. Make sure you are communicating with the right people in an appropriate way.

5) Find the most appropriate highest entry point. If possible, make sure you have a direct line with the most senior responsible person, such as a Minister, which enables you to communicate directly with them. Strengthen the internal communication lines by having contacts at all levels -including, for example, with the director of the Central Bank, to release payments.

6) Work closely with the country team to give you insights into relationships (both between IFAD and government, but also between different people within government).

7) A most powerful tool is the "Thank you" letter to the Minister. This gives you the mandate to follow up if certain agreed actions or contributions are not coming forth. It also makes IFAD's relationship with a Ministry less vulnerable to personnel changes.

8) Broaden the team involved in supporting the partnership and engage a range of IFAD key staff in meetings to help provide IFAD continuity.

\section{SEE}

Tool 6 for more tips on managing and communicating in partnerships 


\section{Partnering with governments in different contexts}

IFAD focuses on low-income countries and lower-middle-income countries, as well as targeting pockets of poverty in upper-middle-income countries. A number of the countries where IFAD works are also fragile and affected by conflict. Such a context will have a significant effect on the nature of the partnership between IFAD and the government, changing the expectations of the partnership and influencing delivery mechanisms. In fragile states and in those affected by conflict, there are significant capacity issues that need to be managed, and IFAD's financial resources will often be critical. In middle-income country contexts, IFAD's financial resources may be less critical, and there will be much more administrative capacity: in these countries, the government will often be looking to IFAD more for technical and policy support.

\section{Fragile contexts}

The table below shows the commonalities and differences of partnering with government in fragile and nonfragile states. In addition to the fragility assessment, this table can help you prioritize actions in your partnership and to remain sensitive towards the challenges that fragility presents to implementing your COSOP.

Table 10.1 Partnering with government in fragile versus nonfragile states

\section{Comparing partnering with government in fragile and nonfragile states}

What is similar?

- Need to consider sustainability and reinforcement of local ownership and capacity

- Long timeframe: interventions take time to deliver results

- Importance of supporting change agents and champions, creating political will, and ensuring ownership

- The complexity of agricultural and rural development and the need for a systems-thinking approach
What is different?

- Pressure to restore services and security quickly

- Short timeframe: more emphasis on short-term relevance of interventions

- Limited capacity to build partnership on (increasing role of TA)

- Often not simply rebuilding, but creating new capacities for partnering

- Little margin for error (e.g., lack of trust, social capital, and institutional resilience)

- Government data is not available or is disputed

- Hyperpoliticized environment

- More IFAD resources required to manage risks.

In fragile countries, IFAD's partnership with a government needs to adjust to the operational realities. Understaffing of government is common, and the government may have limited means to deliver the quality and focus that IFAD usually expects in partnerships with government. Ensure that risks for IFAD are carefully managed while being as adaptive as possible, and be creative in order to avoid being paralyzed by the difficulties that can present themselves on a daily basis. A greater outsourcing to NGOs and private sector organizations may be necessary for delivery, and forms of remote monitoring may be needed.

\section{Middle Income Contexts}

IFAD's partnerships with middle income countries (MICs) - and in particular upper-middle income countries - can be quite different to those with low-income countries (LICs). In MICs, IFAD's technical advice and policy support may be seen as the most valuable contribution, as the government has access to much larger financial resources than the governments of LICs. MICs nonetheless often contain significant levels of rural poverty, so governments may be interested IFAD's role in helping to bring more focus and expertise to agricultural and rural development issues. This may make the use of grant funding particularly important to the IFAD partnerships in MICs. However, grant funding for MICs is also limited, so cofinanced grant-based initiatives should be considered.

It will often be important in MICs to focus on a limited number of key areas where IFAD can add value given limited resources. For example, Morocco wants to close gaps between its regions by creating a new middle class, so the government is interested in youth employment in the agricultural sector, creating a clear niche for IFAD. 


\section{A few trouble shooting tips}

\section{What do you do when things go wrong?}

1) Governments do not like donors coming in with an attitude of 'I am the donor". So talk with respect, focus on the results, and show how you can make them look good. Lead from behind.

2) If a direct counterpart or project manager is not performing or blocking progress, you may have to deal with their supervisor or the most senior responsible person. Find ways of dealing with such situations as tactfully as possible for example, "Your guy is very good, but he is very busy. Can you send someone to help him give attention to this project?" While there is a legal agreement underpinning the partnership, it is usually not effective to threaten government partners.

3) Misprocurement is unacceptable and must be dealt with. Again, as a first resort, try and find a diplomatic way to communicate about this. For example: "We can't accept this, but here is how I can help you ensure conditions are being met (=stay out of trouble)". Refer to IFAD's Code of Conduct and relevant protocols. 


\section{Private sector engagement}

AIM OF THE TOOL

This tool addresses the specifics

of partnering with private sector

actors to leverage market oppor-

tunities and increased invest-

\section{ments.}

WHEN TO USE IT

This tool can be used when

developing partnerships with the

private sector in the Scoping and

Selecting phase, the Setting Up

phase, and the Implementation

phase. It applies on the project,

COSOP, regional, and global

levels.

\section{How this tool can help you}

This tool explains why IFAD partners with the private sector, outlines key considerations for creating successful private sector partnerships, and explains due diligence processes.

Partnering with the private sector is a key part of IFAD's strategy. However, engaging with the private sector will often require a different mindset and approach to partnering with other development actors.

It is helpful to distinguish between two different aspects of working with the private sector: The first is where there is effectively a "deal", in which a private sector actor invests or engages in market systems that IFAD projects are helping to facilitate. The second is where IFAD is hoping to influence the way the private sector operates, or to use the experience and influence of private sector actors to help create more enabling policy conditions. The later will often involve having private sector actors participate in various types of multistakeholder processes that bring together government, civil society, farmer organizations, and the private sector.

There is increasing attention being paid to how IFAD's financial instruments can be employed to play a catalytic role in directing private sector financing into rural micro, small, and medium enterprises, as well as in small-scale agriculture.

However, there are challenges and risks in partnering with the private sector. The quick-acting and entrepreneurial approach of business can clash with the processes and requirements of public institutions and funding. Building partnerships with the private sector requires being able to understand and speak the "language" of business. The bottom-line profit motive of business will not always align with broader public-good objectives, creating the potential for reputational risk. This tool provides guidance on how to handle these challenges and avoid the risks.

Box 11.1: Defining the private sector

In the context of IFAD's Private Sector Strategy, the private sector includes for-profit private business companies, private and institutional investors, commercial banks, investment funds (such as private equity funds, blended finance funds, and impact funds), other financial vehicles that are majority-owned or managed by private entities or interests, and state-owned enterprises with sound financial and governance structures that comply with private sector practices. Private companies may be local, regional, or global. They can also span the spectrum in terms of size, from MSMEs-including cooperatives, corporate farms, and social businesses - to large multinational companies (MNCs).

\section{Why partner with the private sector?}

Achieving SDG 2 is estimated to require an additional annual funding of US $\$ 180$ billion - an amount more than sixteen times the ODA amount allocated to agriculture in 2017. IFAD aims to mobilize private sector financing to help decrease this funding gap, as outlined in its Private Sector Strategy. It is also operationalized through the Private Sector Financing Programme which provides funding in conjunction with PS partners.

On the country level, IFAD engages with the private sector for a range of reasons, including to harness its expertise and efficiencies, mobilize investment capital, and to help provide public goods (such as infrastructure and services) through public-private partnerships. 
Box 11.2: Why would the private sector want to work with IFAD on the country level?

To work with private sector actors, it is important to understand their motivations for partnering with IFAD and collaborating on development projects. Some of these reasons may include the following:

- They see an emerging market opportunity which the partnership can help them access.

- Production from small-scale agriculture is necessary for their supply base, but they find it difficult to work with small-scale farmers effectively.

- They see ways of increasing the efficiency and scale of their operations by partnering.

- Technical or financial support makes it viable to engage in markets that otherwise would not be profitable for them.

- Partnering helps them to reduce the risks of entering a new market.

- Partnering enables them to promote their brand as socially and environmentally responsible.

- For international businesses, the partnership helps to build a positive image and relationship with the host government, giving them a social "licence to operate".

- The partnership can help them create better relations with local communities and have effective consultation processes - for example, in relation to land tenure.
IFAD sees partnering with the private sector as a key strategy in fulfilling its mandate, and has set the following private sector objectives:

1. Mobilize private funding and investments into rural micro, small, and medium-sized enterprises (MSMEs), and into small-scale agriculture.

Action 1: Deploy financial instruments that play a catalytic role in directing private sector financing into rural micro, small, and medium-sized enterprises (MSMEs), and into small-scale agriculture.

Action 2: Use IFAD's programme of loans and grants (PoLG) to crowd in private sector investments.

2. Expand markets and increase income and job opportunities for IFAD's target groups.

Action 1: Develop inclusive value chains with private sector partners.

Action 2: Test and scale up new technologies and cost-effective solutions.

This does not imply that IFAD will partner with just any company. Due diligence is key in getting to know your prospective partners (see TOOL 3). But before you start, consider whether your idea is consistent with IFAD's principles of partnering with private sector.

Worksheet 11.1: Consistency check with IFAD's principles for partnering

IFAD's principles for partnering with private sector

Additionality

Relevance

\section{Development impact}

Environmental, Social, Governance (ESG) standards

\section{Risk}

Key question

Is IFAD bringing added value, given what other sources are already bringing? Does IFAD provide something that market sources are unable or unwilling to offer?

Alignment with COSOPs and government priorities. Alignment with IFAD's mandate.

Scale of expected development benefits to IFAD core target group (smallholder farmers, women, youth, etc.)

What are the effects of the intervention on environmental quality and sustainability? Does the intervention pass IFAD's ESG standards?

What are the risks resulting from the intervention, and are the mitigating measures acceptable? Will the intervention eventually be self-sustaining?

IFAD will carefully assess and mitigate any risks arising from engaging with the private sector, including reputational and financial risks, and those related to mission drift and institutional capacity. 


\section{Steps to engaging the private sector}

The following six considerations for successful business engagement can help you ask the right questions in each stage of your interaction with business. This section also gives some practical tips.

Worksheet 11.2: Steps to engage private sector

Step

\section{Define the development issue}

\section{Analyse the} system or sector, including the role of business

\section{Search for common ground with business}

\section{Assess the business case}

\section{Manage risks and carry out due diligence}

\section{Close the deal}

\section{Consideration}

What is the rural transformation problem, challenge, or opportunity?

Is business relevant to this issue? What role or influence does business have? Is it positive or negative? Could business play a more positive role now or in the future?

What are business' core interests? Where do these intersect this with IFAD's goals? Which of the six partnership objectives can be realized through this partnership?

What kinds of instrument or engagement make the most sense? Does the proposal to realize common interests make sense to IFAD and to the business?

What are the key risks in working with business on this issue? How will the risks be mitigated? What due diligence is necessary?

Make sure all aspects of the partnership agreement are clearly articulated for both IFAD and the business, including arrangements in case the partnership does not work as intended.
Tips

- Articulate the issue clearly, and be prepared to rearticulate it as understanding and dialogue deepens.

- Explore the causes, not just the symptoms.

- Use or reuse TOOL 2 to map the stakeholders

- Understand the political economy of the sector: what are main drivers and who makes the decisions?

- Avoid analysis paralysis: balance the need for sufficient understanding and the need to learn rapidly through conversations with business.

- Understand what motivates business.

- Explore where common interests might lie.

- Funding should not be the starting point for these conversations with business: focus instead on interests.

- Define the expected results for IFAD (and how they fit with COSOP and with regional and global plans).

- Articulate the theory of change, from business engagement to the results being achieved.

- Estimate and track the costs associated with engaging with business.

- See IFAD's due diligence procedures, and Section 5 of this tool below.

- Your insights regarding political economy (Step 2) should flag any key areas of reputational risk.

- Use TOOLS 4 and 5 to develop a good partnership agreement. 
Box 11.3: How a partnership with OLAM came about

"We were introduced to OLAM a long time ago. Our country team in Nigeria challenged us: "please bring the private sector in, our farmers are ready to ship!" Initially we did not understand each other, and the collaboration was a process of trial and error. We needed more patience, which was often not understood by our country team. We were determined to be concrete and clear. This helped to manage expectations, to say upfront that it was difficult. At the same time, our lesson was to make it definite as fast as possible. Find out as soon as you can what the private sector is looking for: do they want grant money? Access to government? Or do they want to coinvest in a fund? Are they looking for something that IFAD can offer? Making this clear required much dialogue and internal coordination.

Another factor in the success of this partnership was that the value chain programme in Nigeria had designated marketing officers. They understood the private sector and were proactive in connecting to companies-even in cold calling. IFAD needs a combination of technical specialists and 'hustlers' if it's to be an attractive partner to sourcing companies. If you don't have marketing staff, get started with an intern from a business school."

based on interviews with Nicole Carta and Ben Odoemena

\section{Tips for dialogue with private sector}

Despite the notion that the private sector is different from IFAD, people working in it are like any of us - they have workloads, tempers, emotions, and interests. Much of the success of your conversations with the private sector thus depends on communication skills that would apply anywhere.

The result of good dialogue is clarity of action, which eventually results in a deal between IFAD and the company. This deal could be about many things: about IFAD and the business exchanging information on a wide range of issues, about one-off and regular events, about IFAD and the business pooling their knowledge and experience to develop new solutions, or about IFAD and the business coinvesting in a project. In order to arrive at a deal, you need to know exactly what you want out of the conversation. But this paradoxically means that you need to listen first, in order to understand where the common ground and business case are for IFAD (see the previous section).

Here are a few tips from IFAD colleagues on how to bring the dialogue to a fruitful conclusion:

Tip 1: Move out of your comfort zone and just get out there. Then follow through with your request; don't be afraid to call people back if you haven't heard back from them. Don't give up when you heard 'no' a few time-this is part of the game. It's called prospecting.

Tip 2: Understand the business you're talking to. Be clear about where the people you talk to are located in the organization (core business or CSR department), and whether they make the decisions on the issue you care about. Determine how the responsibilities are divided between their global and country operations.

Tip 3: Involve people who speak the language of the private sector. This could be as simple as taking on a business school intern, or joining a local business network. This teaches you to be decisive and hard-nosed: to be clear about what IFAD represents, and to have facts about farmers, productivity, and the market ready to share.

Tip 4: Surprise people with your efficiency and speed. While establishing a partnership may require patience, always make sure to act quickly on the matters you have promised to perform. Actions build more trust than words.

Tip 5: Go to your GPR team contact, as they have the tools and can open doors (do this with questions like "who is procurement lead for cocoa in Ghana?")

Tip 6: Watch this two-minute interview with experienced IFAD colleagues on engaging business, still relevant although it is from 2014: http://youtu.be/RIWmIPgIejQ. 


\section{Performing a due diligence check}

A due diligence check can help IFAD to identify potential partners who are aligned in their values and have a shared vision of impact. This is an important but easily overlooked step amidst the enthusiasm for the benefits of the collaboration. Use IFAD's due diligence procedures for further guidance.

\section{Ask hard questions}

- What are the meaningful drivers that motivate the private sector to engage in the partnering process? Understanding these deeper issues provides important context as to why companies should engage with IFAD, devote resources, invest time, and share risk.

\section{Investigate on both the operational and personnel levels}

- If a potential partner has a history of unethical operations, poor performance, or limited leadership, it is important to consider how their participation might affect the partnership.

\section{Assess the risks and rewards of partnership}

- All partners anticipate that the rewards of engaging in a partnership will outweigh the potential risks.

- Since brands become comingled in a partnership, it is important for IFAD not to overlook the potential risks. These can include reputational damage, loss of influence, and heavy upfront investment of resources.

\section{Decide on your focus}

- Due diligence can be carried out on social risks (like worker exploitation and child labour), on environmental risks (such as polluting production processes and deforestation), on financial risks (for IFAD), and on any other dimension that may involve a reputational risk for IFAD. The focus of due diligence will depend on the situation.

- Look at IFAD's Private Sector Strategy, which includes a section on Risks and Mitigating Measures. Also refer to IFAD's due diligence procedures.

\section{Who conducts due diligence?}

Remember that, in many situations, on the country level, it is likely to be your governmental partner that has the mandate for carrying out due diligence on potential private sector partners.

Nevertheless, the risk for IFAD is the same, as the organization will still be associated with any reputational issues that might emerge.

IFAD's GPR team can assist with due diligence. For larger companies, IFAD can run reports from IFAD's business intelligence service subscriptions. For smaller local companies, there are checklists available from GPR to help you.

Where to go from here?

This is a crosscutting tool, which means that it spans the different partnership phases. TOOL 1 provides an overview of these phases, and can point you a tool that is specific to the phase your partnership is in. 


\section{Participation in complex multistakeholder partnerships}

AIM OF THE TOOL

To improve the value-for-invest-

ment of IFAD's participation in

multistakeholder partnerships

(MSPs).

WHEN TO USE IT

In all phases of the partnership

cycle, especially in complex MSPs with many partners.

\section{How this tool can help you}

IFAD's engagement in multistakeholder partnerships, such as platforms, alliances, and networks, can be a very strategic way of furthering IFAD's objectives. However, there are so many such partnerships on the global, regional, and national levels that it is critical for IFAD to be clear on why it is engaging and how to optimize value from participation. Multistakeholder partnerships (MSPs) can be time consuming, and at times are slow to show results, so understanding how to effectively facilitate and guide them is important.

We distinguish three roles for IFAD in MSPs:

(1) MSPs where IFAD initiates and sets up the process;

(2) MSPs where IFAD is part of an MSP initiative, and can exert some control;

(3) MSPs initiated by others, where IFAD only participates.

This tool is especially useful if you want to get the most out of your time investment in an MSP, depending on the role that IFAD chooses to play.

\section{MSP: a specific form of partnership}

In IFAD's Partnership Framework, the term partnership can refer to a bilateral partnership with individual institutions, as well as to engagement in a multistakeholder network or platform. This tool focuses on the latter, and uses the generic term multistakeholder partnerships.

Such MSPs may be formed on the global, regional, or country levels. They usually address issues that are cross-sectorial and involve different stakeholders, such as the public sector, the private sector, knowledge institutions, and civil society. MSPs have grown particularly strongly within in the business sustainability agenda, with companies entering collaborations to tackle the human, social, infrastructure, and environmental challenges to the sustainability of their operations.

To date, there has been a proliferation of MSPs initiated on the global level. Many of these have sought to drive their agenda across regions and countries - at times with a top-down approach. However, increasingly MSPs are emerging at country and local levels as well. On the local level, they can take full account of the local context, being built up more organically on the basis of needs, resources, and the energy available-a bottom-up approach. A number of global partnerships, such as Scaling Up Nutrition, are trying to combine the global approach to achieving scale with the local approach to being locally relevant and sustainable, enabling vertical integration of efforts.

Examples of MSPs that IFAD participates in

- The Committee on World Food Security (CFS), an intergovernmental multistakeholder platform with both civil society and private representation.

- African Union Development Agency-NEPAD (AUDA-NEPAD)

- The New Partnership for Africa's Development (NEPAD)

- Global Donor Platform for Rural Development

- Country-level UN coordination platforms
Examples of MSPs hosted by IFAD

- The Platform for Agricultural Risk Management (PARM), a G20 initiative.

- Financing Facility for Remittances (FFR), a multidonor initiative with the EU, Luxembourg, Spain and Sweden. 
Table 12.1: IFAD roles in MSPs

Three roles that IFAD can play in MSPs

1. IFAD itself sets up and manages the MSP process

2. IFAD is part of an MSP initiative, or is helping to structure one, and thus has some influence.

\section{IFAD only participates.}

Different degrees of complexity require different approaches to the design and development of a partnership. Partnering around a 'complex' issue, for example, requires more of a 'big tent' approach where dialogue is key. By contrast, 'simple' issue partnerships can achieve a clearer focus and are more geared towards implementing concrete action plans. Where does your issue sit on the complexity spectrum?
Tips

Follow this toolkit: Ensure that you use good partnering practice, as outlined in the partnership cycle used in this toolkit. Focus on setting the right priorities with partners, agreeing on realistic planning, and investing in relationships.

Use worksheet $\mathbf{1 2 . 1}$ below to determine how important this MSP could become for IFAD. This helps you to articulate the partnering value for each of the six partnership objectives. If it is high priority, allocate extra staff time in order to do a good job contributing to this MSP (by following this toolkit), and safeguard IFAD's interests in it.

Be conscious about playing IFAD's role as best you can so as to get the most out of it. Make sure you monitor and review the MSP, using TOOL 9 to assess the value for IFAD. Does it justify the time investment?

\section{Simple}

\section{Complex but bounded}

There are a larger number of ac-

There are a small number of actors and there is clarity on what needs to be done, how to do it, and the resources and roles required to deliver it tors, but the scope of the problem

is sufficiently bounded, specific, and understood for stakeholders to be able to agree to align around a designed collective impact initiative (e.g., developing a new value chain)

\section{Complex unbounded}

There is no clear boundary to the system, there are multiple issues and stakeholders, and there is limited potential to align around one large designed programme with agreed common objectives (e.g., food system transformation)

\section{Alignment of an MSP with IFAD's objectives}

As a starting point in assessing whether to setup or participate in an MSP, consider how the partnership will contribute to IFAD's partnering objectives. Explore what IFAD needs to get out of the MSP for it to be worthwhile, and what is likely to be needed for such results to be achieved.

\section{IFAD's six partnering objectives}

1. Influence policy and development agendas

2. Leverage financial resources

3. Enable coordinated country-led development processes

4. Generate knowledge and innovation

5. Strengthen private sector engagement

6. Enhance visibility
Worksheet 12.1 (next page) helps you think through the value of your MSP using these six objectives. Also see TOOL 2 for background on these objectives, and worksheet 2.1 for guidance on identifying partnering outcomes and needs 
Worksheet 12.1: What is the partnering value of this MSP for IFAD?

IFAD partnership objective

1. Influence policy and development agendas

2. Leverage financial resources

3. Enable coordinated country-led development processes

\section{Generate} knowledge and innovation

\section{Strengthen private} sector engagement

\section{Enhance visibility}

Here is an example:

1. Influence policy and development agendas

2. Leverage financial resources

3. Enable coordinated country-led development processes

\section{Generate} knowledge and innovation

5. Strengthen private sector engagement

6. Enhance visibility

\section{Does this MSP}

help to reach this objective?

\section{YES $\square$ NO}

$\square$ YES $\square$ NO

\section{$\square$ YES $\square$ No}

\section{$\square$ YES $\square$ NO}

$\square$ YES $\square$ NO

\section{$\square$ YES $\square$ No}

How?

(Describe the value of this MSP for IFAD) 


\section{How MSP partnering can create value for IFAD}

Here are a number of ways an MSP can create value in terms of the issue being addressed. When you look at these eight types of value creation below, ask yourself do any other benefits come to mind that IFAD could aim for in your MSP?

1. Innovation: combining partners' diverse resources leads to more innovative approaches, including market-based solutions

2. Systemic transformation: complex situations require coordinated activities from multiple organizations and communities to shift the conditions that hold a problem in place

3. More appropriate, implementable solutions: more experience and thinking being brought in; broader buy-in from key stakeholders

4. Learning, capacity building, and the creation of norms and standards: supports replication and avoids reinventing the wheel
5. Weight of action: multiple resources effectively focused on a single outcome (such as advocacy or creating a stronger voice)

6. Combining essential resources, including essential nonpurchasable resources (like social capital)

7. Greater efficiency: coordinating action; sharing resources; economies of scale; exploiting synergies.

8. Sustainability and scale: potential for taking viable models to scale or to the mainstream (for example, through social enterprise model)

9. Anything else?

\section{Preparing for and following up on MSP events}

You get out of it what you put into it! Preparation and follow up are essential to getting the best out of the MSPs that IFAD participates in. For MSP events-be it the World Committee for Food Security or a national level agriculture sector coordination committee-don't just "turn-up"; instead, think ahead about the issues and agendas that IFAD wants to work on, who you need to have side discussions with, and what IFAD needs to do to ensure that the event itself is a success and adds value. Good preparation may require engaging with other stakeholders prior to the event. Find out who from IFAD is attending and, for larger events, determine the roles and responsibilities of the different delegation members.

At country, regional, and global levels, establish an annual plan for key MSP events. There will often be connections between different platforms, networks and events, and IFAD's agenda's may be more effectively advanced with a coordinated approach. Such thinking ahead can also enable the prioritization of different events and avoid ad hoc last minutes responses. IFAD does not have the capacity to effectively engage in all of the MSP events to which it is invited, so prioritization is critical.

Many MSP initiatives struggle because of lack of follow up after the energy of face-to-face gatherings. Where IFAD is facilitating an MSP, find ways of ensuring there are processes and capacities for follow-up. Where IFAD is participating, create a follow-up action plan, and make sure outcomes are communicated back within IFAD. 


\section{Tips for keeping momentum in complex MSPs}

There is widespread acknowledgement that MSPs that engage different stakeholders across government, business, civil society, research, and farmer organizations are critical to achieving development outcomes. At the same time, there is recognition of the challenges found in keeping up momentum and ensuring that these processes achieve results. There is much that can be done to improve the process and facilitation for MSPs. If you are responsible for supporting an MSP, it may be worth familiarizing yourself with good practices. The MSP Guide provides a good overview and many practical tools.

Here are some basic tips:

1. Always keep IFAD's goal for participation in an MSP in mind. Remind MSP participants why this MSP is important to IFAD.

2. Don't forget to communicate what's happening in the MSP back in IFAD. Too often, staff actively representing IFAD in MSP are so busy on the fringes of the organization that they are at risk of becoming isolated, and thus lose internal support.

3. It is possible that the MSP's vision and goals are sound, but that its interaction design is failing. Think about the type of conversations that need to happen for this MSP to deliver results. What formats would be required to make these conversations a reality? Box 12.1 shows a range of options for activities that could be tried out to reinvigorate your MSP:

Box 12.1: Types of MSP activities and events: options for design

- Preparation and planning meetings involving those who are initiating, organizing, or facilitating the MSP.

- Individual or small group meetings with people whose support and influence are critical.

- Meetings of a steering or advisory group established to help guide and support the overall MSP process.

- Multistakeholder workshops involving various combinations of relevant stakeholders.

- Single-stakeholder workshops that enable a single group or sector to prepare for engaging in the MSP.

- Working groups that undertake specific organizational, research, or communication activities.

- Field visits and study tours.

- Seminars or conferences that engage a wider audience.

- Media events.
4. Be strategic about positioning yourself in the niche where IFAD is unique. The contribution of IFAD to an MSP can be undirected, but more results can be expected from a targeted effort to negotiate what IFAD can bring to this MSP that others cannot. In return, this can help you to identify clear goals and results from this MSP, which will be important in the Monitoring and Review phase.

5. Sometimes going slowly together is the best way, even if we think we can do it faster ourselves. MSPs can take a notoriously long amount of time, and often move at slow pace. Still, there comes a time to consider whether the return on investment is sufficient to justify the investment of IFAD's resources.

6. MSPs sometimes disappoint. In such cases, it may be wise for IFAD to withdraw. This decision should always be based on a thorough assessment of the value that the MSP is bringing to IFAD, and in terms of the development results. Be aware: it is possible for a lack of results to be the result of factors internal to IFAD - such as IFAD not investing enough time and resources to make the MSP work, or interpersonal issues between IFAD staff and other partners in the MSP.

7. Here are the seven principles for effective partnering from The MSP Guide. Consider all seven thoughtfully, and address them in your MSP design and implementation. This will help prevent stagnation, underperformance, ineffectiveness, and elite capture:
1. Embrace systemic change
2. Transform institutions
3. Work with power
4. Deal with conflict
5. Communicate effectively
6. Promote collaborative leadership
7. Foster participatory learning. 


\section{References}

Several tools in this toolkit have drawn inspiration from existing literature, as referenced below. In all cases, tools have been adapted to fit IFADs working processes.

\section{General}

Brouwer, Herman and Jim Woodhill, Minu Hemmati, Simone van Vugt, Karèn Verhoosel (2019, 3rd edition) The MSP Guide: How to design and facilitate multi-stakeholder partnerships. Wageningen Centre for Development Innovation/ Practical Action. www.mspguide.org/msp-guide

IFAD (2016) How to do Note: Public-PrivateProducer Partnerships (4Ps) in Agricultural Value Chains: Sustainable inclusion of smallholders in agricultural value chains. www.ifad.org/en/web/ knowledge/publication/asset/39433604

\section{Introduction and TOOL 1}

IFAD (2019) IFAD Partnership Framework, specifically Appendix V. https://webapps.ifad.org/ members/eb/127/docs/EB-2019-127-R-4.pdf

TOOL 2

IFAD (2019) IFAD Partnership Framework https://webapps.ifad.org/members/eb/127/docs/ EB-2019-127-R-4.pdf

Tennyson, Ros (2003-2011) The Partnering Toolbook: An essential guide to cross-sectoral partnering. International Business Leaders Forum/ The Partnering Initiative. Page 43. https://thepartneringinitiative.org/publications/ toolbook-series/the-partnering-toolbook/

\section{TOOL 3}

WWF (2009) The Partnership Toolbox. By Rod Sterne, Deborah Heaney and Bruce Britton. www.fsnnetwork.org/partnership-toolbox

TPI Internal prospective partnership assessment. https://thepartneringinitiative.org/internalprospective-partnership-assessment-tool-2/

\section{TOOL 4 \& 5}

IFAD (2019) IFAD Partnership Framework https://webapps.ifad.org/members/eb/127/docs/ EB-2019-127-R-4.pdf
TOOL 6

McManus, Sue and Ross Tennyson (2008) Talking the walk: A communication manual for partnership practitioners. International Business Leaders Forum/The Partnering Initiative. https://thepartneringinitiative.org/publications/ toolbook-series/talking-the-walk/

Menden, Aline; Nelleke van der Vleuten, Christian Pirzer, Isabel von Blomberg (2019) NGO and Company partnerships for inclusive business. Eneva/Partos/Bayer/iBAN. https://endeva.org/publication/ngo-companypartnerships-inclusive-business

The SDG Partnership Guidebook (2020) provides guidance on how to build robust and effective collaborations: https://thepartneringinitiative.org/publications/ toolbook-series/the-sdg-partnerships-guidebook/

Tennyson, Ross (2011) The Partnering Toolbook: An essential guide to cross-sector partnering. International Business Leaders Forum. https://thepartneringinitiative.org/publications/ toolbook-series/the-partnering-toolbook/

\section{TOOL 7}

Based on interviews with IFAD staff: Naoufel Telahigue, Bernard Hien, Massimo Giovanola, Mauro Martini.

Fisher, Roger; William L. Ury; and Bruce Patton (1991) Getting to Yes: Negotiating Agreement Without Giving In. London: Penguin Group.

\section{TOOL 8}

Kusters, Cecile; Karen Batjes; Seerp Wigboldus; Jan Brouwers; Sylvester D. Baguma (2017) Managing for Sustainable Development Impact: An integrated approach to planning, monitoring and evaluation. Wageningen: Wageningen Centre for Development Innovation, and Rugby (UK): Practical Action. https://research.wur.nl/en/publications/managingfor-sustainable-development-impact

\section{TOOL 9}

TPI Partnership health check https://thepartneringinitiative.org/thepartnership-health-check/

WWF (2009) The Partnership Toolbox. By Rod Sterne, Deborah Heaney and Bruce Britton. https://www.fsnnetwork.org/resource/partnershiptoolbox p.21-24. 
TOOL 10

PPPlab (2018) Partnering with Governments for SDGs tool

https://ppplab.org/2018/07/partnering-with-

governments-for-sdgs-tool/ (used for tool 12:2)

Interviews with IFAD staff Naoufel Telahigue, Bernard Mwinyel Hien, Massimo Giovanola, Mauro Martini (October 2019).

Brinkerhoff, D. (2007) Capacity Development in Fragile States. Discussion paper No 58D May 2007, prepared for the project 'Capacity, Change and Performance' of ECDPM.

https://ecdpm.org/wp-content/uploads/2013/11/DP58D-Capacity-Development-in-Fragile-States-2007. pdf (used for tool 12:5)

IFAD (2016) Rural Development Report 2016: Fostering inclusive rural transformation. Specifically Spotlight \#4 on Fragile Situations, p 185-190.

https://www.ifad.org/en/web/knowledge/publication/ asset/39240288 (Used for tool 12:5)

\section{TOOL 11}

IFAD (2016) How to do Public-Private-Producer Partnerships (4Ps) in Agricultural Value Chains www. ifad.org/en/web/knowledge/publication/asset/39433604

IFAD (2019) Private Sector Strategy 2019-2024 www.ifad. org/en/document-detail/asset/39500277

Interviews with IFAD staff Nicole Carta (New York, Private Sector Partnerships) Ben Odoemena (Country Programme Manager, Nigeria, ESA Region) and Willem Wefers Bettink (Rome, Global Engagement, Partnership and Resource Mobilization (GPR) division)

\section{TOOL 12}

TPI Context analysis for partnering https://thepartneringinitiative.org/context-analysistool (used for Tool 12:2 and 12:4)

IFAD (2019) IFAD Partnership Framework https://webapps.ifad.org/members/eb/127/docs/EB2019-127-R-4.pdf

The MSP Guide, p 24, and p 40-117 (used for Tool 12:6) (see above) 